\title{
Identifying Clusters of Regions in the European South, based on their Economics, Social and Environmental Characteristics
}

\author{
Vasilis Angelis ${ }^{1}$, Athanasios Angelis-Dimakis ${ }^{2}$, Katerina Dimaki ${ }^{3}$ \\ ${ }^{1}$ University of the Aegean, Chios, Greece (e-mail: v.angelis@aegean.gr) \\ 2 University of Huddersfield, Huddersfield, UK (e-mail: a.angelisdimakis@hud.ac.uk) \\ ${ }^{3}$ Athens University of Economics and Business, Athens, Greece (e-mail: dimaki@aueb.gr) \\ Received: 11 May 2015/Accepted: 20 October 2016
}

\begin{abstract}
Regional development has been the focal point of both academics and decision makers in the central and local governments of many European countries. Identifying the key problems that regions face and considering how their solutions could be effectively used as a basis for planning their development process, are essential in order to improve their conditions. The growth of a region depends on its ability to attract and retain both business units and the right blend of people to run them. In this context, we introduced a variable which is referred to as the image of a region and quantifies its attractiveness. A region's image depends on a variety of factors, economic, social, and environmental, some of which are common for all potential movers and some specific for particular groups, and expresses its current state of development and its future prospects. The paper examines a number of south European countries and focuses on their NUTS 2 level regions. Its objective is to estimate the image values of those regions and to group them into different clusters on the basis of the characteristics used to define their image. The results are presented and discussed.
\end{abstract}

JEL classification: C02, C65, Q01, R58

Key words: Regional Development, Region's Image, Cluster Analysis, South European Regions

\section{Introduction}

For many years regional development has been linked to economic prosperity but this attitude has been gradually changing. Many societies underwent very deep and far reaching changes which have led to the need for redefining the concept of development and have brought up the concept of sustainability. This refers to the capability of a region to satisfy the needs of the present without, however, jeopardizing the right of the future generations to meet their own expectations. Measuring sustainable development is not an easy task as it requires overcoming the simple unidimensional economic description of human activities and incorporating social and environmental dimensions as well. It also requires novel techniques which could benchmark performance, identify cases of growth and recession on the aforementioned dimensions of development, and pinpoint the best 
practices. Furthermore, new tools should be developed which could lead to more objective, robust, and reliable decision making.

In Angelis, Dimaki (2011) the nature of the functions of a region as a socioeconomic unit has been discussed in detail. Every region carries out a number of functions; economic, social, and environmental (Kotler et al. 1999, Boschma, Lambooy 1999). The relative importance of those functions has not remained constant over time. Initially the economic function was the dominant, but gradually the social started gaining in importance. Recently the environmental function emerged as the third pole of development. Furthermore, the region's functions are not always compatible; on the contrary the idea of a conflict between the economic, on one hand, and the social and environmental, on the other, is widespread in literature (Llewellyn 1996, Lovering 2001, Bristow 2005).

The process of business and residential location has been presented in detail in Angelis, Dimaki (2011). The development of a region depends on its power to attract business activities and the right blend of people to run them (Malecki 2004, Bristow 2005). Business location has been traditionally dependent on economic factors, such as easy access, availability of land, labor and capital, and infrastructure. Lately, however, a number of social and environmental factors have gained in importance. Similarly, residential location has been traditionally dependent on a set of employment related factors, such as availability/quality of jobs and level of salaries. Over the last years, however, this set has been enriched by other factors, such as quality of life, housing availability/quality, and educational services (Burgess 1982, Bristow 2010). Moreover, a set of "attraction" factors seem to be common for both business units and employees. This set comprises of healthy economy, easy access, reliable infrastructure, good living conditions, and social amenities. The choice of location by a group of prospective movers (i.e. business or employees) seems to consist of two steps. The first step leads to a short list of candidate locations, which satisfy a set of basic criteria common to all groups, while the second step leads to the best choice for the particular group (Malecki 2004). The paper presents the concept of a region's image, a composite measure of the region's overall trend towards sustainable development, which encompasses two dimensions: economic and social, and suggests ways for its measurement. Image, as defined in Angelis, Dimaki (2011), has two distinct characteristics. It allows for possible discontinuities in the development of a region and it uses methods and techniques, which can tackle them.

Following this brief introduction, Section 2 presents and discusses the concept of a region's image, as a measure of its ability to attract business activities and the right blend of people to run them and goes on to refine it by introducing the concepts of Basic and Specific Image. The Basic Image, which we will focus on in this paper, is defined as a function of two potentially conflicting indicators, Economic and Social, each depending on a number of factors expressing the region's economic and social profile, respectively. Section 3 presents the general model of a region's Basic Image. Based on evidence provided in the authors' earlier works that a region's Basic Image may exhibit nonlinear behavior, it has been modeled in terms of Catastrophe Theory (the general mathematical theory of discontinuous behavior resulting from continuous underlying forces) and indeed as a Cusp Catastrophe. Section 4 adapts the general model presented in the previous section to the case of the four south European countries under study, namely Greece, Italy, Portugal, and Spain. This adaptation was needed since data availability for all four countries was, in certain cases, limited and this determined, to a large extent, the quantification of the regions' two indicators and eventually of their Basic Image. The variables chosen are stated, their selection is justified, their measurement, aggregation and normalization methods are presented, and their conversion into the two Indicators and finally into the region's Basic Image is outlined. Section 5 focuses on the sixty NUTS 2 level regions of the four countries under study, calculates, in the way described in the previous section, their Economic and the Social Indicator values, and finally uses the proposed model to estimate their Basic Image values. The results are presented and discussed. Section 6 goes on to the clustering of all sixty regions on the basis of their economic and social characteristics which have been used for the quantification of their Economic and Social Indicators, respectively, and comments on the findings. Section 7 summarizes the overall results and discusses potential policy implications while Section 8 
presents the conclusions and suggests areas for further research.

\section{The concept of a region's image}

The development of a region, as already mentioned, depends on its ability to "attract" and "keep" healthy businesses and competent human resources to run them. This ability is a function of the region's image. This term has been used over time in different ways. Many researchers consider it as a sum of beliefs, ideas, and impressions, or as the total impression an entity makes on the mind of people, which exerts an influence on the way they perceive it and react to it (Dowling 1998, Dichter 1985). Marketing researchers, in particular, refer to place images and make a distinction between projected and received images (Kotler et al. 1993). The former can be seen as ideas and impressions available for the receivers' assessment and transmitted to them through various communication channels. The latter, on the other hand, are shaped by the interaction of the "projected" images and the particular needs, motivation, prior knowledge, experience, and personal characteristics of every receiver. In this way every receiver creates its own personal image (Ashworth, Voogd 1990, Gartner 1993, Bramwell, Rawding 1996). The concept of a region's Image or, in other words, of its power to pull and retain businesses and employees appears in literature as a variable under different names, like "attractiveness", "competitiveness", and "quality of life". In most of the cases, it is expressed as a composite indicator referring to specific groups of potential movers (business units or residents/employees) or specific aspects of the region's function (economic, social, and environmental) (Dijkstra et al. 2010, Lagas et al. 2015, Annoni, Kozovska 2010). Furthermore, multivariate analysis has been used to evaluate the regions' performance (del Campo et al. 2008, Morais, Camanho 2011). This paper defines image in a different way that is as a function of objectively measured factors affecting the movement of both business activities and employees. Obviously, a region's image may be improved through marketing and promotion but only temporarily. The only lasting improvement is the "real" and objective endorsement of the region's image attributes which increases its competitiveness and makes it a "sticky place" for business and people (Markusen 1996, Malecki 2004). Since a region's image is received by many groups of potential movers with varying characteristics, wishes, and priorities, it is obvious that each of those groups perceive it in a different way. Hence we can say that, effectively, a region does not have an image but multiple images (Dowling 1998). On the basis of all those mentioned so far we may say that a region "transmits" its image, which is perceived and assessed by its receivers, and is accordingly classified as attractive or non-attractive. At this point someone may argue that since the receivers belong to different groups with distinct characteristics their assessment of the same region's image would vary (Kotler et al. 1999, Bryson et al. 2007). This is a reasonable argument but, on the other hand, the available evidence shows that all those receiving the region's image have a set of common basic criteria which should be satisfied if the region is to be considered, by any of them, as a potential final choice. (Kotler et al. 1999, Schneider, White 2004). In order to bridge those two seemingly opposing views, the concept of a region's image has been refined by introducing the concepts of Basic and Specific Image. The Basic Image expresses the extent to which a region meets the criteria common to all its receivers and hence it may enter their shortlist of potential final choices. The Specific Image, as perceived by a particular group of movers, expresses the degree to which the region will be the final choice for the members of this group.

The rest of the paper will concentrate on a region's Basic Image, a rather abstract concept which expresses the actual state of the region. A physically realizable measure for the Basic Image is difficult to find; what may be measured more easily is the net change of a region's population and industrial stock during each time period. Such a change, however, is of very little importance as a measure of the real state of the region. The perception and reaction times to any change in the state of a region's Basic Image are different for the various groups of potential movers and are particularly long for certain vulnerable minorities, without any real choice of the place to live and work. Hence, the measurable changes of the region's population and industrial stock may be generally considered as the delayed and considerably smoothed consequence of changes in the Basic 
Image. The novelty and the main advantage of a region's Basic Image is that it gives an early warning of any potential problems and at the same time helps the decision makers to detect the causes and the symptoms of those problems. An early and correct diagnosis of a problem is perhaps the biggest step towards its solution. In the case of regional development, however, the seeds of decay are usually planted during a period of prosperity and no action is taken to prevent them until it is too late. Ironically, the very state of being an attractive place may unleash forces that ultimately unravel the attractiveness of a place. Many places experience a period of growth, followed by a period of decline, and the fluctuations may be repeated several times. Therefore, a monitoring device, which will alert us at the first sight of danger, is a tool of great importance. By keeping a region's Basic Image attractive, we may argue that in spite of any fluctuations in the various specific factors and/or of any unforeseen external adversities, the region may retain its overall attractiveness, redirect its strategy and finally overcome the difficulties. If, on the other hand, its Basic Image becomes non-attractive, the region enters a vicious circle of fall and decline.

On the basis of all those mentioned so far, a region's Basic Image may be expressed as a number of factors classified into two groups depending on whether they refer to the economic or the social/environmental function of the region. The factors of the first group, properly measured and scaled, give a measure of the $i^{\text {th }}$ region's economic profile known as its Economic Indicator $\left(I N D_{i}^{1}\right)$. Similarly, the factors of the second group give a measure of the $i^{t h}$ region's socio-environmental profile, known as its Social Indicator $\left(I N D_{i}^{2}\right)$. Hence, the Basic Image is a function of its Economic and Social Indicators i.e. Basic Image $=\phi\left(I N D_{i}^{1}, I N D_{i}^{2}\right)$. The expression of the Basic Image as a function of those two Indicators is not accidental; on the contrary, it is consistent with the concept of a region as a socio-economic unit. The main advantage of such an expression is that it may be used to underline and, eventually, describe the potential conflict between the economic and social functions of a region in the course of development (Llewellyn 1996, Lovering 2001, Bristow 2005). The factors to be included in each group as well as their measurement, aggregation, and normalization methods will be presented in Section 4 . Concluding this section it should be mentioned that the growth of a region may be expressed in both absolute and relative terms. For the purposes of this work we are interested in the latter case or, in other words, in the development of a given region with respect to the "typical" region (Angelis, Dimaki 2011). This is a fictitious region representative of the regions under study, in the sense that the values of its indicators are the average of the respective indicator values of all those regions. Hence all the factors comprising the Basic Image of a given region will be expressed in relative terms in comparison to the corresponding values of the "typical" region.

\section{Modeling a region's Basic Image}

Having defined a region's Basic Image as a function of two indicators, the next step will be to get a first idea of the shape of its graph. Obviously, the higher/lower the value of each or both indicators, the higher/lower the value of the Basic Image and consequently the higher/lower the region's attraction. On the contrary, when the values of the two indicators follow opposite trends, no clear conclusions may be drawn for the value of the region's Basic Image; hence the region may be alternating from attractive to non-attractive and sudden changes in the value of its Basic Image may be expected. The latter statement is obviously more important as it indicates that the graph under consideration could be discontinuous. Furthermore, evidence has been provided (Angelis, Dimaki 2011) that the mechanism generating a region's Basic Image may be modelled in terms of Catastrophe Theory and indeed as a Cusp Catastrophe (Thom 1975, Zeeman 1973, Gilmore 1993, Poston, Stewart 2012), since it possesses all the required properties. Catastrophe theory was developed and popularized in the early 1970's. After a period of criticism, it is now well established and widely applied (Rosser 2007). Today, the theory is very much alive and numerous nonlinear phenomena that exhibit discontinuous jumps in behavior have been modeled by using the theory, for instance in chemistry (e.g. Wales 2001), in physics (e.g. Aerts et al. 2003), in psychology (e.g. van der Mass et al. 2003) in 
clinical studies (e.g. Smerz, Guastello 2008) and in the social sciences (e.g. Smith et al. 2005, Dou, Ghose 2006, Huang 2008, Bełej, Kulesza 2013). Returning to the present case, the value $x_{i}, i=1, \ldots, n$, of the $i^{t h}$ region's Basic Image at a given time is deduced as a solution of the Basic Image equation:

$$
x_{i}^{3}-B x_{i}-A=0
$$

with,

$$
\left\{\begin{array}{l}
A=m\left(I N D_{i}^{1}-I N D_{0}^{1}\right)+\left(I N D_{i}^{2}-I N D_{0}^{2}\right) \\
B=\left(I N D_{i}^{1}-I N D_{0}^{1}\right)-m\left(I N D_{i}^{2}-I N D_{0}^{2}\right)
\end{array} \text { if } m \leq 1\right.
$$

and

$$
\left\{\begin{aligned}
A & =m\left(I N D_{i}^{1}-I N D_{0}^{1}\right)+(1 / m)\left(I N D_{i}^{2}-I N D_{0}^{2}\right) \\
B & =(1 / m)\left(I N D_{i}^{1}-I N D_{0}^{1}\right)-\left(I N D_{i}^{2}-I N D_{0}^{2}\right)
\end{aligned} \text { if } m>1\right.
$$

where:

$I N D_{i}^{1}$ : The Economic Indicator for the $i^{t h}$ region;

$I N D_{i}^{2}$ : The Social Indicator for the $i^{t h}$ region;

$I N D_{0}^{1}$ : The Economic Indicator for the "typical" region;

$I N D_{0}^{2}$ : The Social Indicator for the "typical" region; and

$m$ : expresses the relative weights attached to each of the two indicators in defining the Basic Image.

It is noted that the Economic and Social Indicators values of all regions lie in the interval $[0,1]$ while their respective Basic Image values in the interval $[-1,+1]$. Furthermore, the Economic and Social Indicators of the typical region are calculated as the average of the respective indicators' values of all regions under study while its Basic Image value is zero (Angelis, Dimaki 2011). Hence, a region with positive Basic Image value is attractive and potentially a final choice for some group of prospective movers. Finally, for the purposes of the present work, the relative weights attached to each of the two indicators are equal, and hence $m=1$.

Going a step further we can say that each indicator may be expressed as the geometric mean of several sub-indicators, each one depending on a number of factors among those affecting the region's Basic Image. The use of geometric mean is justified by the fact that each of them is considered to be critically important for this indicator's value. Consequently,

$$
I N D_{i}^{h}=\sqrt[m]{\prod_{j=1}^{m} S b I_{i j}^{h}} \quad h=1,2, \quad i=1, \ldots, n
$$

where $I N D_{i}^{h}$ denotes the $h^{t h}$ indicator of the region $i$ and $S b I_{i j}^{h}$ denotes the $j^{\text {th }}$ subindicator of the region $i$ which is related to the indicator $h$. Each sub-indicator $S b I_{i j}^{h}$ is defined as a nonlinear function of a respective relative index $R I_{i j}^{h}$, which in turn, is a function of all variables, measured or estimated, affecting the sub-indicator and may be defined in the following two ways:

- The values of all variables, expressed in relative terms with respect to the typical region, are used to obtain directly the relative index $R I_{i j}^{h}, h=1,2, i=1, \ldots, m$.

- The variables are grouped into various sets, depending on the particular component of the sub-indicator they affect. The values of all variables belonging to a specific set, expressed in relative terms with respect to the typical region, are used to obtain directly the respective relative sub-indices $R S I_{i j k}^{h}, h=1,2, i=1, \ldots, n$, 
$j=1, \ldots, m, k=1, \ldots, r$. Finally, those sub-indices are combined so as to give the corresponding relative index:

$$
R I_{i j}^{h}=\frac{\sum_{k=1}^{r} w_{k} R S I_{i j k}^{h}}{\sum_{k=1}^{r} w_{k}} ; \quad h=1,2, \quad i=1, \ldots, n, \quad j=1, \ldots, m
$$

where, $w_{k}, k=1, \ldots, r$ are weights indicating the relative importance attached to each sub-index in defining the respective relative index.

By normalizing the relative index $R I_{i j}^{h}$, the sub-indicator $S b I_{i j}^{h}$ is obtained. The normalisation is needed in order to ensure that:

- All sub-indicators have the same range. For the purposes of this work, all subindicators have the same range value, namely $[0,2]$; hence, the range of their product is $\left[0,2^{n}\right]$ and, consequently, the range of $I N D_{i}^{h}, h=1,2, i=1, \ldots, n$ is also $[0,2]$. In certain cases, however, the dominance of a particular sub-indicator needs to be emphasized. This may be done by increasing its range. In such a case, the range of the remaining sub-indicators must be modified, so that the range of their product remains the same i.e. $\left[0,2^{n}\right]$.

- The effect of changes in the values of variables on the respective sub-indicators follows the same pattern for all sub-indicators.

\section{The proposed model for the case of the south European regions}

Having presented the model for the estimation of a region's Basic Image, we will now proceed with its adaptation to this particular case. As already mentioned, this adaptation was needed since data availability for all four countries was, in certain cases, limited and this determined, to a large extent, the quantification of the regions' two indicators and eventually of their Basic Image. Let us start with the Economic Indicator which, as already mentioned in Section 2, should depend on factors related to the economic function of a region. For the purposes of this particular case, three factors will be considered, namely the region's level of economic development, the emphasis placed on research and development, and its accessibility to large centers. Each of them is expressed through a respective sub-indicator. The three factors and the corresponding sub-indicators are presented below.

Economic Development: The level of the economic development and financial robustness of a region seems to affect the locational choices of both business units and employees and it is measured in different ways. In this particular case, it is quantified through an appropriate sub-indicator. The Economic Development sub-indicator of the $i^{\text {th }}$ region, $\left(S b I_{i 1}^{1}\right)$, is a nonlinear transformation of the Relative Economic Development index $\left(R I_{i 1}^{1}\right)$, which is defined as the region's gross domestic product per capita, expressed in relative terms.

Research and Development: While the region's GDP is an indication of its current financial status, the emphasis placed by the region on research and development is an indication of its future prospects, in the sense of its readiness to adapt to the changing conditions of the dynamic business environment. In this particular case, the region's emphasis on research and development is quantified through the Research and Development sub-indicator $\left(S b I_{i 2}^{1}\right)$. It is a nonlinear transformation of the Relative Research and Development index which is defined as the $i^{\text {th }}$ region's expenditure on R\&D as percentage of its GDP, expressed in relative terms.

Accessibility: Easy access to large centers seems to be one of the factors that both businesses and employees take into account when deciding to move into or out of a region. The concept of "easy access" appears in literature under different names such as accessibility, proximity, or connectivity and is measured in different ways. In this paper, it appears as "accessibility" and it is quantified through the 
Location sub-indicator of the $i^{t h}$ region, $\left(S b I_{i 3}^{1}\right)$. It is a nonlinear transformation of the Relative Location index $\left(R I_{i 3}^{1}\right)$, which expresses the region's relative position with respect to the various influence centers. Every region is generally surrounded by more than one influence centers. Hence, the Relative Location index expresses the total influence exerted on region $i$ by all influence centers. In other words, the Relative Location index is the sum of $r$ Relative Location sub-indices $\left(R S I_{i 3 k}^{1}\right)$, $k=1, \ldots, r$, each one expressing the influence exerted on the $i^{t h}$ region by the respective influence center $k$. Hence,

$$
R I_{i 3}^{1}=\sum_{k=1}^{r} R S I_{i 3 k}^{1} ; \quad i=1, \ldots, n
$$

Furthermore, each of the Relative Location sub-indices is a function of:

- The influence center's size, as defined by its Gross Domestic Product, expressed in relative terms.

- The region's accessibility to the given influence center, which depends on the cost of transporting a unit quantity between the $i^{\text {th }}$ region and the given influence center, expressed in relative terms and the degree of a region's spatial discontinuity, as defined by the transport modes available and their transportation capacity, expressed in relative terms.

Having completed the presentation of the factors/sub-indicators affecting the $i^{\text {th }}$ region's Economic Indicator, we will now proceed with the Social Indicator which is considered as a function of four factors; health services, educational conditions, poverty, and environmental conditions, expressed through the respective sub-indicators. The four factors and the respective sub-indicators are presented below.

Health Services: The level of the region's health services is one of the main factors affecting directly the employees' locational choices and indirectly the employers' decisions. The level of health services provided may be measured in different ways and in this particular case is quantified through an appropriate sub-indicator. The Health Services sub-indicator $\left(S b I_{i 1}^{2}\right)$ is a nonlinear transformation of the Relative Health Services index which is defined as the $i^{t h}$ region's health personnel per inhabitant as expressed in relative terms.

Educational Conditions: The level of educational conditions is also among the factors exerting a strong direct influence on the employees' locational decisions and, at the same time, an equally strong indirect influence on the business units' decisions. Many different ways have been used for its measurement and in this particular case it is quantified through the Educational Conditions sub-indicator $\left(S b I_{i 2}^{2}\right)$. It is a nonlinear transformation of the Relative Educational Conditions Index which is defined as the $i^{t h}$ region's ratio of population with secondary and tertiary education, expressed in relative terms.

Poverty: The GDP/capita used for the quantification of the $i^{\text {th }}$ region's Economic Development sub-indicator certainly gives an aggregate and overall view of its financial status. Such an aggregate measure, nevertheless, may hide inequalities and, in certain extreme cases, may distort the picture. The level of poverty in the region gives an indication of the equity in income distribution. This may be measured in different ways and in this particular case is quantified through an appropriate sub-indicator. The Poverty sub-indicator $\left(S b I_{i 3}^{2}\right)$ of the $i^{\text {th }}$ region is a nonlinear transformation of the Relative Poverty Index of the $i^{\text {th }}$ region which is defined as the region's population at risk of poverty and social exclusion, expressed in relative terms.

Environmental Conditions: As mentioned in the introduction, every region performs three main functions: economic, social, and environmental with the latter gaining in importance recently. Hence, although environment does not appear as a distinct 
Table 1: The Economic Indicator of region $i$

$$
I N D_{i}^{1}=\sqrt[3]{\prod_{j=1}^{3} S b I_{i j}^{1}}, \quad i=1, \ldots, n
$$

$I N D_{i}^{1} \quad$ The Economic Indicator of region $i=1, \ldots, n$

$S b I_{i 1}^{1} \quad$ The Economic Development sub-indicator of region $i$. The transformed data used are based on the GDP per inhabitant.

$S b I_{i 2}^{1} \quad$ The Research \& Development sub-indicator of region $i$. The transformed data used are based on the R\&D expenditure as percent of GDP.

$S b I_{i 3}^{1} \quad$ The Accessibility sub-indicator of region $i$. The transformed data used are based on the distance from the large influence centers and modes of transport available (land, sea, air).

Table 2: The Social Indicator of region $i$

\begin{tabular}{ll}
$\qquad I N D_{i}^{2}=\sqrt[4]{\prod_{j=1}^{4} S b I_{i j}^{2}}, \quad i=1, \ldots, n$ \\
\hline$I N D_{i}^{2}$ & $\begin{array}{l}\text { The Social Indicator of region } i=1, \ldots, n \\
S b I_{i 1}^{2}\end{array}$ \\
& The Health Services sub-indicator of region $i$. The transformed data used are \\
based on the health personnel per 100,000 inhabitants.
\end{tabular}

dimension in this case, we have included it as a component in the Social Indicator. Environmental conditions may be measured in different ways and in this particular case are quantified through the Environmental Conditions sub-indicator $\left(S b I_{i 4}^{2}\right)$, a nonlinear transformation of the Relative Environmental Conditions Index which is defined as the region's expenditure on environmental protection as percentage of its GDP, expressed in relative terms. At this point, it should be mentioned that, as part of their ongoing research, the authors have been experimenting with removing the environmental conditions from the Social Indicator and introducing a new third Environmental Indicator based exclusively on environment-related factors. In this case, the Basic Image may be defined as a function of three indicators Economic, Social, and Environmental and modeled in terms of a Butterfly Catastrophe (Angelis et al. 2013).

On the basis of all the above, the Economic and Social Indicators for the case of the south European regions may be expressed as shown in Tables 1 and 2, respectively. A clear overview of the variables affecting a region's development and their conversion, through relative indices and sub-indicators into indicators and finally into the region's Basic Image, is given in Table 3.

We have so far used a number of factors to define a region's Economic and Social Indicators and hence its Basic Image. However, one may argue that a number of important factors such as unemployment rates, labor quality and availability, salaries, and financial incentives have been left out. This is a plausible argument but it should be reiterated that the Basic Image, as defined, measures the degree to which the region satisfies the criteria that are common for all potential movers and hence it should be a function of factors affecting, almost to the same extent, both business units and employees. Important factors which have been left out and seem to affect primarily some of the groups of potential movers will be used for the estimation of the respective Specific Images. In this respect, employment rates, and level of salaries as well as housing quality and availability may be 
Table 3: Variables affecting region's $i$ development and their conversion into its Economic and Social Indicators

\begin{tabular}{|c|c|c|c|}
\hline \multicolumn{4}{|c|}{ INDICATORS, INDICES AND VARIABLES CONCERNING REGION } \\
\hline Indicators of region $i$ & $\begin{array}{l}\text { Sub-indicators of } \\
\text { region } i\end{array}$ & $\begin{array}{l}\text { Relative Indices of } \\
\text { region } i\end{array}$ & Variables \\
\hline \multirow{3}{*}{$\begin{array}{l}\text { Economic Indicator } \\
\left(I N D_{i}^{1}\right)\end{array}$} & $\begin{array}{l}\text { Economic } \\
\text { Development } \\
\text { sub-indicator }\left(S b I_{i 1}^{1}\right)\end{array}$ & $\begin{array}{l}\text { Relative Economic } \\
\text { Development index } \\
\left(R I_{i 1}^{1}\right)\end{array}$ & $\begin{array}{l}\text { Gross Domestic } \\
\text { Product, Population }\end{array}$ \\
\hline & $\begin{array}{l}\text { Research and } \\
\text { Development } \\
\text { sub-indicator }\left(S b I_{i 2}^{1}\right)\end{array}$ & $\begin{array}{l}\text { Relative Research and } \\
\text { Development index } \\
\left(R I_{i 2}^{1}\right)\end{array}$ & $\begin{array}{l}\text { Expenditure on R\&D, } \\
\text { Population }\end{array}$ \\
\hline & $\begin{array}{l}\text { Accessibility } \\
\text { sub-indicator }\left(S b I_{i 3}^{1}\right)\end{array}$ & $\begin{array}{l}\text { Relative Accessibility } \\
\text { index }\left(R I_{i 3}^{1}\right)\end{array}$ & $\begin{array}{l}\text { Size of Influence } \\
\text { Centers, Distance/Cost } \\
\text { from Influence Centers }\end{array}$ \\
\hline \multirow{4}{*}{$\begin{array}{l}\text { Social Indicator } \\
\left(I N D_{i}^{2}\right)\end{array}$} & $\begin{array}{l}\text { Health Services } \\
\text { sub-indicator }\left(S b I_{i 1}^{2}\right)\end{array}$ & $\begin{array}{l}\text { Relative Health } \\
\text { Services index }\left(R I_{i 1}^{2}\right)\end{array}$ & $\begin{array}{l}\text { Health Personnel, } \\
\text { Population }\end{array}$ \\
\hline & $\begin{array}{l}\text { Education Conditions } \\
\text { sub-indicator }\left(S b I_{i 2}^{2}\right)\end{array}$ & $\begin{array}{l}\text { Relative Education } \\
\text { Conditions index } \\
\left(R I_{i 2}^{2}\right)\end{array}$ & $\begin{array}{l}\text { Population with upper } \\
\text { secondary and tertiary } \\
\text { education, Population }\end{array}$ \\
\hline & $\begin{array}{l}\text { Poverty sub-indicator } \\
\left(S b I_{i 3}^{2}\right)\end{array}$ & $\begin{array}{l}\text { Relative Poverty index } \\
\left(R I_{i 3}^{2}\right)\end{array}$ & $\begin{array}{l}\text { Population at risk of } \\
\text { poverty or social } \\
\text { exclusion, Population }\end{array}$ \\
\hline & $\begin{array}{l}\text { Environmental } \\
\text { Conditions } \\
\text { sub-indicator }\left(S b I_{i 4}^{2}\right)\end{array}$ & $\begin{array}{l}\text { Relative Environ- } \\
\text { mental Conditions } \\
\text { index }\left(R I_{i 4}^{2}\right)\end{array}$ & $\begin{array}{l}\text { Expenditure on } \\
\text { Environment, GDP }\end{array}$ \\
\hline
\end{tabular}

used for the estimation of the residents' Specific Image whereas labor quality/availability and financial incentives may be used for the calculation of the business activities' Specific Image. It must be reiterated that the Specific Image of a given region, as perceived by a group of potential movers, measures the degree to which movers belonging to that particular group consider the region as their best final choice. The Specific Image however, although a function of selected factors, appealing mainly to the members of that group, is primarily a function of the region's Basic Image. Maintaining and improving a region's Basic Image is not an easy task. However, all efforts to improve the conditions, through the improvement of Specific Image factors have limited and temporary effect and the only effective and long lasting solution is the improvement of the Basic Image factors (Angelis et al. 2015).

\section{Estimating the Basic Image values of the south European regions}

The methodology presented in the previous sections, has been used for the estimation of the Economic Indicator, the Social Indicator, and the Basic Image values of the NUTS 2 level regions of four south European countries namely, in alphabetical order, Greece, Italy, Portugal and Spain, for 2012. Those countries have in total sixty regions distributed among them as shown in Table 4. The required data have been drawn from the official site of Eurostat. For each of the sixty regions under study the primary data have been successively converted, as described in Section 4 and Table 3, into relative indices and sub-indicators and eventually (according to Tables 1 and 2) into the Economic and Social indicators. The Economic and Social indicators of the "typical" region have been also calculated and found to be 0.495 and 0.485 respectively. The values of each region's indicators together with the typical region's respective indicators have, in turn, been used for the calculation of the coefficients $A$ and $B$ of equation (1), whose solution has given the region's Basic Image values. The results are summarized in Tables A.1 and A.2 of the Appendix. Table A.1 contains the values of the Economic and Social Indicators for the south European regions for the year under study which are also graphically depicted 
Table 4: Number of regions per country

\begin{tabular}{lc}
\hline Countries & \# of regions \\
\hline Spain & 19 \\
Italy & 21 \\
Greece & 13 \\
Portugal & 7 \\
TOTAL & 60 \\
\hline
\end{tabular}

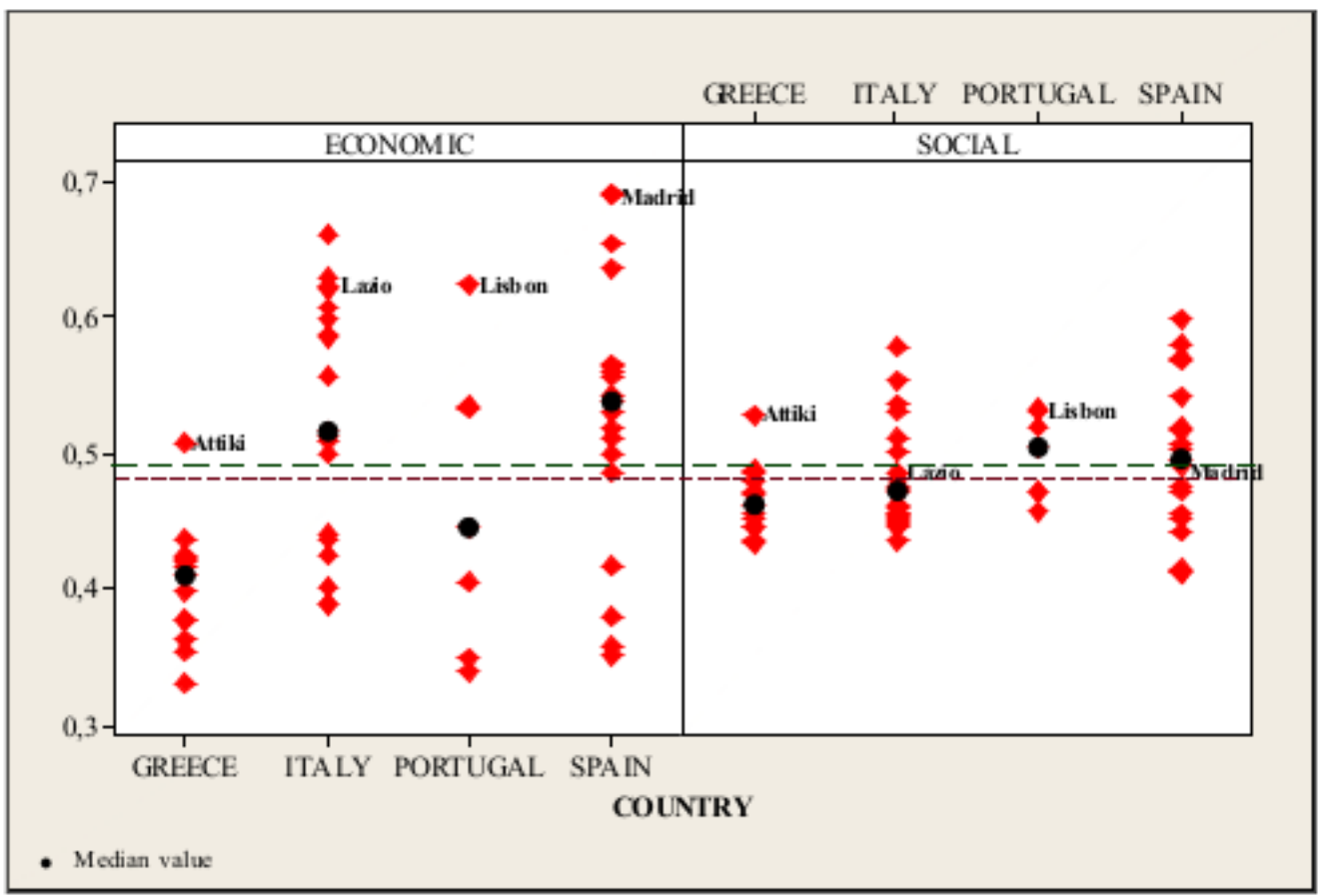

Figure 1: The Economic and Social Indicators of the 60 south European regions

in the Figures A.1 and A.2 of the Appendix. Table A.2 presents the values of the Basic Image for all south European regions and for the year under study. As a reminder, the "typical" region's Basic Image value is zero.

The Economic Indicator values of the Spanish and Italian regions range from about 0.35 to 0.70 (Figure 1). This wide range shows strong regional heterogeneity but the small gaps between successive regions indicate the lack of a dominating region. Moreover, the regions seem to be assembled in three distinct groups. Portugal's regions exhibit a similar range of Economic Indicator values but also a distinct gap between the leading capital region and all the rest as well as small but sizeable gaps between the successive regions. The Economic Indicator values of the Greek regions extend over a narrower range (0.35-0.50) but the large gap between the leading capital region and all the rest indicates its clear dominance. Furthermore, more than $50 \%$ of the regions in Spain and Italy have Economic Indicators' values greater than 0.495 , which is the value of the typical region's Economic Indicator (denoted by the upper dotted line in Figure 1); whereas in Greece and Portugal this occurs only in one and two regions, respectively. The corresponding median values are shown in Figure 1. Finally, the capital regions in all four countries have high Economic Indicators values: the highest values in Greece and Portugal, the second highest in Spain, and third highest in Italy.

The Social Indicator values of the Spanish and Italian regions range from about 0.40 to 0.60 , without any discontinuities between them (Figure 1). On the contrary, the Social Indicator values of the Greek and Portuguese regions extend over a narrower range (0.45-0.55) but with a noticeable gap between the leading region (or regions) and all the 


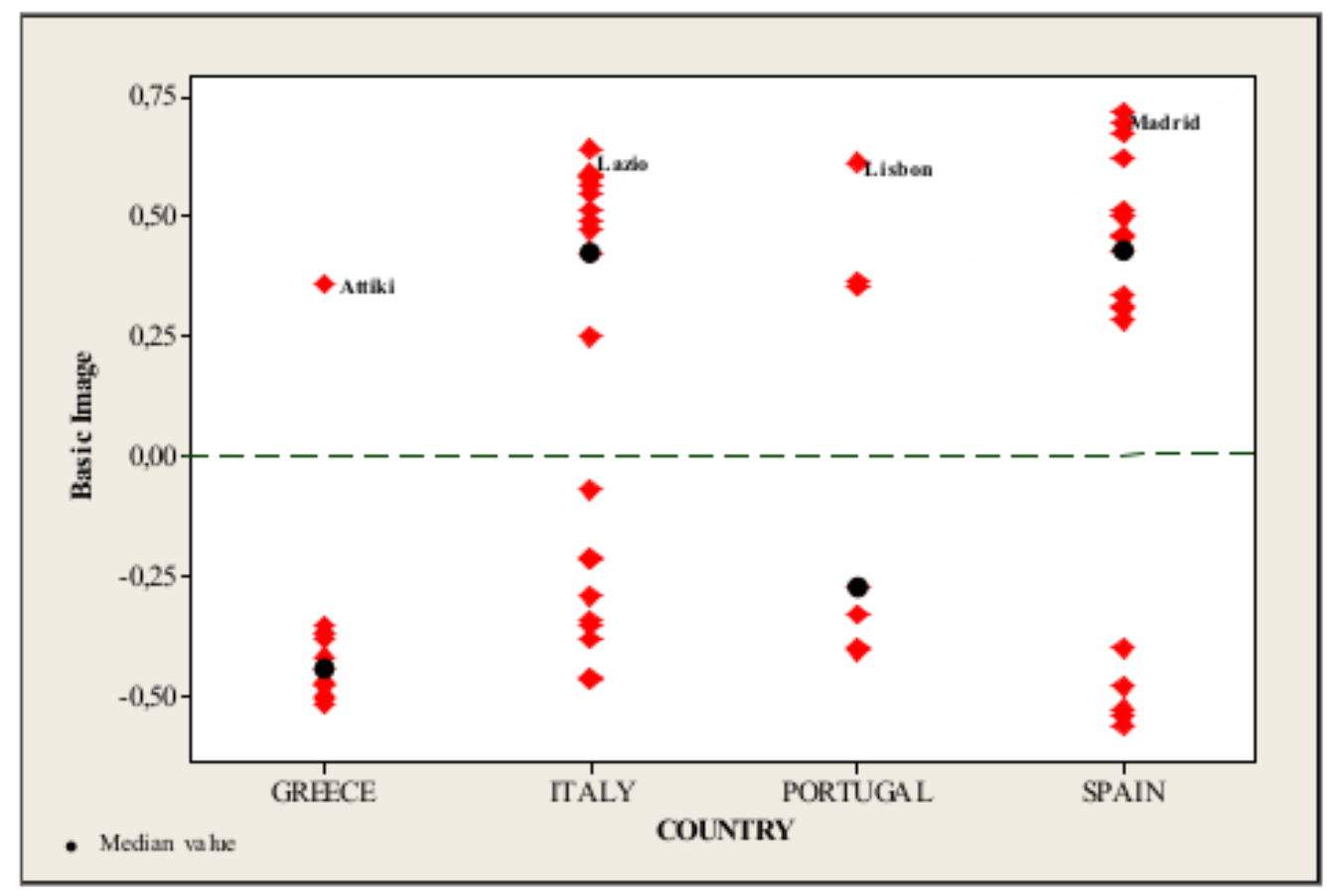

Figure 2: The Basic Image of the 60 south European regions

rest. More than 50\% of the regions in Spain and Portugal have Social Indicator values greater than 0.485 , which is the value of the typical region's Social Indicator (denoted by the lower dotted line in Figure 1). The respective ratios in Italy and Greece are about $35 \%$ and $25 \%$. The corresponding median values are shown in Figure 1. Finally, the capital regions have the highest Social Indicators values in Greece and Portugal but considerably lower in Italy and Spain (Figure 1). At this point it should be noted that the range of the Social Indicator's values in all countries is narrower than the respective range of Economic Indicator. This is an interesting but easily explainable observation. The three factors comprising the Economic Indicator move, in most of the cases, in the same direction. In other words, regions with high economic activity usually combine high accessibility, good financial conditions, and investment in $R \& D$ whereas a region with low economic activity faces the opposite situation. This leads to extreme values, both high and low, for the Economic Indicators thus widening their range. On the contrary, the four factors comprising the Social Indicator move in different directions. In most of the cases, regions with high economic growth exhibit improved health services and educational conditions but low poverty and environmental conditions, and the opposite happens in regions with low economic activity. This leads to a smaller gap between the leading and lagging regions with respect to the Social Indicator and to a narrower range of their values.

The Basic Image values of Spanish, Italian and Portuguese regions extend over a wide range from about -0.55 to 0.70 indicating a strong regional heterogeneity (Figure 2). Moreover, in all three countries the regions seem to be assembled in two distinct groups separated by a big gap. It should also be noted that Portugal exhibits a smaller range of values and in contrast to the other two countries a dominance of the capital region. Finally, the Basic Image values of the Greek regions extend over a narrower range from about -0.50 to 0.35 and the large gap between the capital region and the rest indicates the dominance of this region. Furthermore, more than $60 \%$ of the regions in Spain and Italy have positive Basic Image values (the typical regions' Basic Image value is zero and it is denoted by the dotted line in Figure 2). The respective percentage for Portugal is about $40 \%$ whereas in Greece only the capital region exhibits positive Basic Image. The corresponding median values are shown in Figure 2. Finally, the capital regions in all four countries have high Basic Image value; the highest values in Greece and Portugal, 
Table 5: Classification of the south European regions according to their Basic Image value

\begin{tabular}{lccccc}
\hline $\begin{array}{l}\text { The Basic Image } \\
\text { lies in the } \\
\text { interval: }\end{array}$ & Greece & Italy & Portugal & Spain & Total \\
\hline$[-1.0,-0.5)$ & 3 & - & - & 3 & 6 \\
{$[-0.5,0)$} & 9 & 9 & 4 & 2 & 23 \\
{$[0,0.5)$} & 1 & 4 & 2 & 7 & 15 \\
{$[0.5,1)$} & - & 8 & 1 & 7 & 16 \\
Total & 13 & 21 & 7 & 19 & 60 \\
\hline
\end{tabular}

the second highest in Italy and Spain.

The Basic Image values of all sixty south European regions, which may be found in Table A.6 of the Appendix, are summarized in Table 5 and graphically depicted in Figure 3. A final comment on the Basic Image results may be that our model seems to underestimate the values of all island regions. This is due to the fact that the negative impact of spatial discontinuity has been built into our model's Economic Indicator, thus reducing its value and hence the Basic Image value in the case of island regions. A second run of the model with a relaxed Economic Indicator, taking into account only the distance of the regions from the main influence centers and not their geographical discontinuity, improves the Basic Image values of island regions, but not significantly. This happens because most of the islands in the four countries under study are located far from large influence centers and this keeps their accessibility at low level despite the spatial discontinuity relaxation. However, most of the island regions focus on the attraction of business activities for which unfavorable location is not necessarily a handicap. Tourism is such an activity, for which distance, isolation and geographical discontinuity may not be a problem, but on the contrary, in certain cases a strong comparative advantage. Hence, the current model must be modified for the case of island regions.

Looking at the similarities between the patterns of the Economic Indicator and the Basic Image values, one may argue that there is no reason of calculating a region's Basic Image if we know that a high Economic Indicator (or even a high GDP) leads to a high positive Basic Image. The answer to that is very simple. A high Economic Indicator leads to a positive Basic Image only if the Social Indicator exceeds a given value. A drop of the Social Indicator (which in many cases may be the outcome of an excessive and uncontrolled increase of the region's economic growth) below a given threshold may lead to a sudden jump in the value of the Basic Image, which however, will be realized much later and as a smooth change. This is due to the long and different times needed by the members of each group of potential movers to perceive changes in a region's Basic Image value and react to them, which naturally leads to a smooth and delayed aggregate behavior. A closer and more careful look at the Economic Indicator and the Basic Image values for Greece and Portugal confirms this argument. In the case of Portugal, the better overall Social Indicators of its regions, as compared to Greece, leads to an improvement of the Basic Image values of some of its lagging regions and hence a closer gap between them and the leading regions in comparison with the gap of their respective Economic Indicator values. On the contrary, in the case of Greece, the low values of its regions' Social Indicators cannot have any positive effect on their Basic Image values thus widening their gap, as compared to the gap of the respective Economic Indicator values. A similar reasoning may explain the differentiation of the pattern of the Basic Image values for Spanish and Italian regions with respect to their Economic Indicator values. On the basis of all the above it could be said that the great importance of calculating both indicators and the Basic Image is to have an overall view of the region's development, get, through the Basic Image, an early warning of any potential dangers, identify, through the respective indicators and sub-indicators, the causes of these potential dangers and finally take the necessary measures to overcome the problems thus maintaining and improving the Basic Image.

Concluding this section we will refer to the robustness of our model and to its sensitivity 


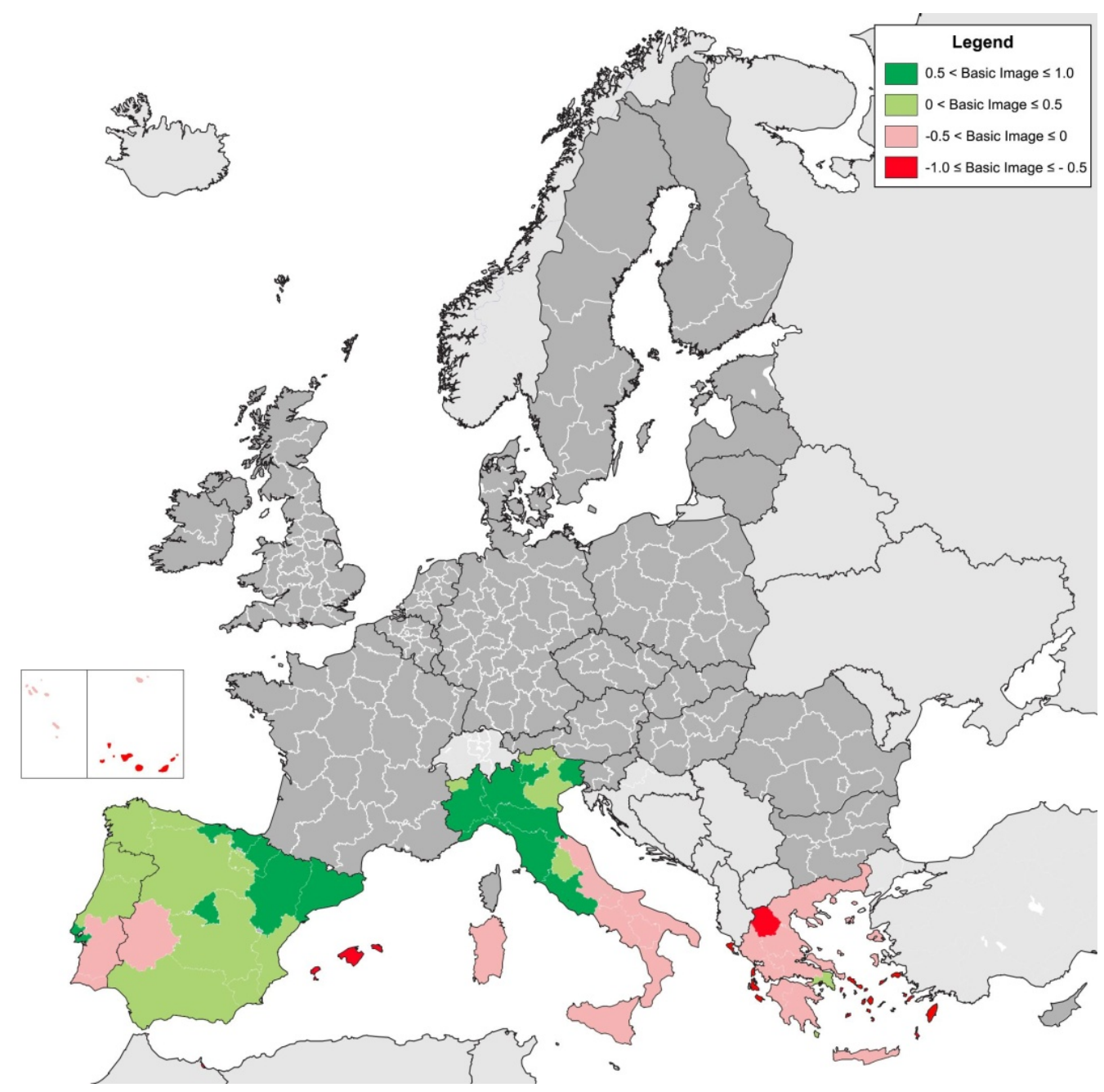

Figure 3: Classification of the south European regions according to their Basic Image value

to any changes in the selection and measuring of the variables affecting a region's Basic Image. The building of composite indicators involves a series of steps and decisions, most of which are arbitrary. Such decisions concern, among other things, the selection of the variables used as well as of the methods of weighting, aggregating, and normalizing the data. Hence, sensitivity analysis is needed in order to assess the extent to which those decisions might affect the values of those indicators, the model results, and hence, the conclusions drawn on the basis of those results.

In the context of this paper, three types of sensitivity analysis have been carried out (Charron et al. 2015, Dijkstra et al. 2010, Lagas et al. 2015). In the first case, a fourth factor expressing the Quality of Government has been added to the Economic Indicator, thus making it a function of four sub-indicators. In the second case, the environmental factor has been removed from the Social Indicator, thus making it a function of three sub-indicators (Charron et al. 2014, 2015). Finally, in the third case, the Accessibility Sub-indicator has been relaxed by taking into account only the distance of the regions from the main influence centers and not their geographical discontinuity. In each case, the values of the modified indicators have been re-estimated and the model was applied in order to estimate the regions' Basic Image values. The results obtained in all cases indicate the robustness of the model and its limited sensitivity to the changes described. Obviously there are some variations in certain values but no significant changes in the overall trends and no switches in the regions' Basic Image signs. An indicative comparative view of the Basic Image values as given by the base model (using a three factor Economic Indicator) 
and the test model, where a fourth factor (Quality of Government) has been added, is presented in Figure 4.

\section{Identifying the economic and social profiles of the south European regions}

Having calculated the Basic Image values of all the 60 regions under study we will now go on to their clustering on the basis of their economic and social characteristics which have been used for the quantification of their Economic and Social Indicators, respectively. To that end the Hierarchical Clustering method was initially used to determine, through a dendrogram, the number of emerging clusters and was followed by the $k$-means method which assigned the regions in the various clusters. Finally, the means of selected economic characteristics were compared in order to identify differences between clusters.

\subsection{The economic profile of the south European regions}

Let us start with the economic profile of the regions under study. Following the first two steps described above, the regions may be classified according to their economic characteristics into three clusters EC1, EC2 and EC3 (Figure A.3). The findings are summarized in Table A.3 and graphically depicted in Figure 5.

In order to identify the differences between the three clusters, the following hypotheses were tested:

H0: There is no difference in the means of the economic characteristics of the regions belonging to clusters EC1, EC2, EC3.

H1: There is difference in the means of the economic characteristics of the regions belonging to clusters EC1, EC2, EC3.

Based on Table 6 (summary report) and Figure 6 the following conclusions may be drawn:

- Cluster EC1 contains 13 regions (i.e. 21.7\%). These are regions with very good economic profile, as the mean values of all relevant variables are considerably higher than the respective overall mean values. Furthermore, the dispersion of those variables' values is low in the case of Economic Development (5.7\%) and higher in the case of Research \& Development and Accessibility (10.6\% and 10.2\% respectively).

- Cluster EC2 contains 22 regions (i.e. 36.7\%). These are regions with average economic profile, as the mean values of all variables expressing this profile, are only marginally higher than the respective overall mean values. Furthermore, the dispersion of those variables' values is high in the case of Economic Development $(16.0 \%)$ and lower in the case of Research \& Development and Accessibility $(13.8 \%$ and $10.2 \%$ respectively).

- Cluster EC3 contains the remaining 25 regions (i.e. 41.6\%). These are regions with poor economic profile, as the mean values of all variables expressing this profile, are lower than the respective overall mean values. Furthermore, the dispersion of those variables' values is low in the case of Economic Development $(8.2 \%)$ and much higher in the case of Research \& Development and Accessibility (18.5\% and 20.0\% respectively).

This classification shows the clear superiority of cluster EC1 over the clusters EC2 and EC3 and the superiority of cluster EC2 over the cluster EC3. The cross tabulation (by country) leads to Table 7 .

As we can see from Table 7 and Figure 5, the clusters EC1 and EC2 (i.e. the clusters of regions with average and high economic profile), contain 35 regions or $58 \%$ of the total number or regions in all four countries. Most of the regions of Spain (78.9\%) and Italy (71.05\%), over half of the regions of Portugal (57.1\%) but only one in Greece $(7.7 \%)$ and no island regions, in any of the countries, belong to this group. Furthermore, in all four 


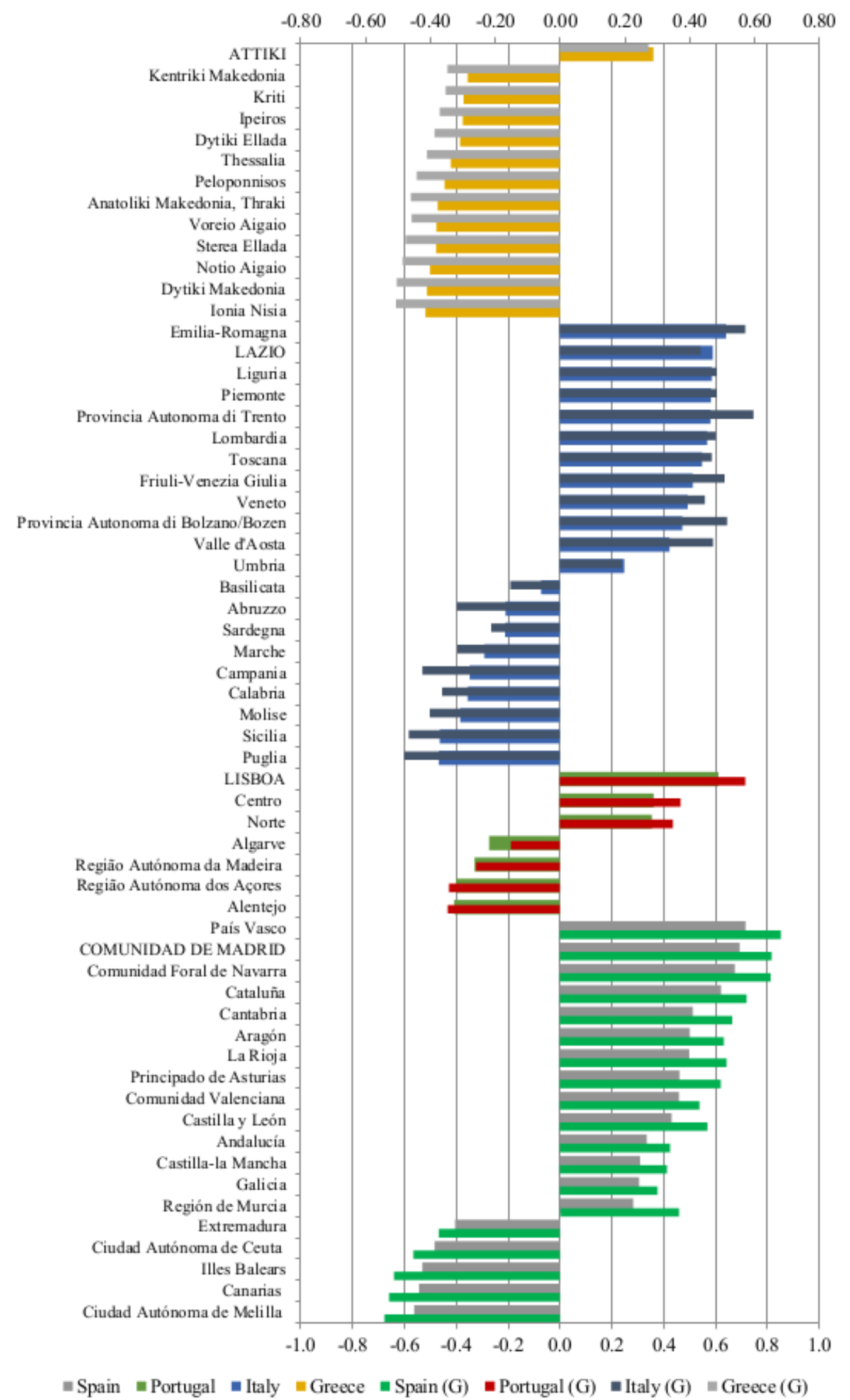

Figure 4: Basic Image values given by the model when using a three and a four-factor Economic Indicator respectively. The latter values are denoted by $(\mathrm{G})$ 


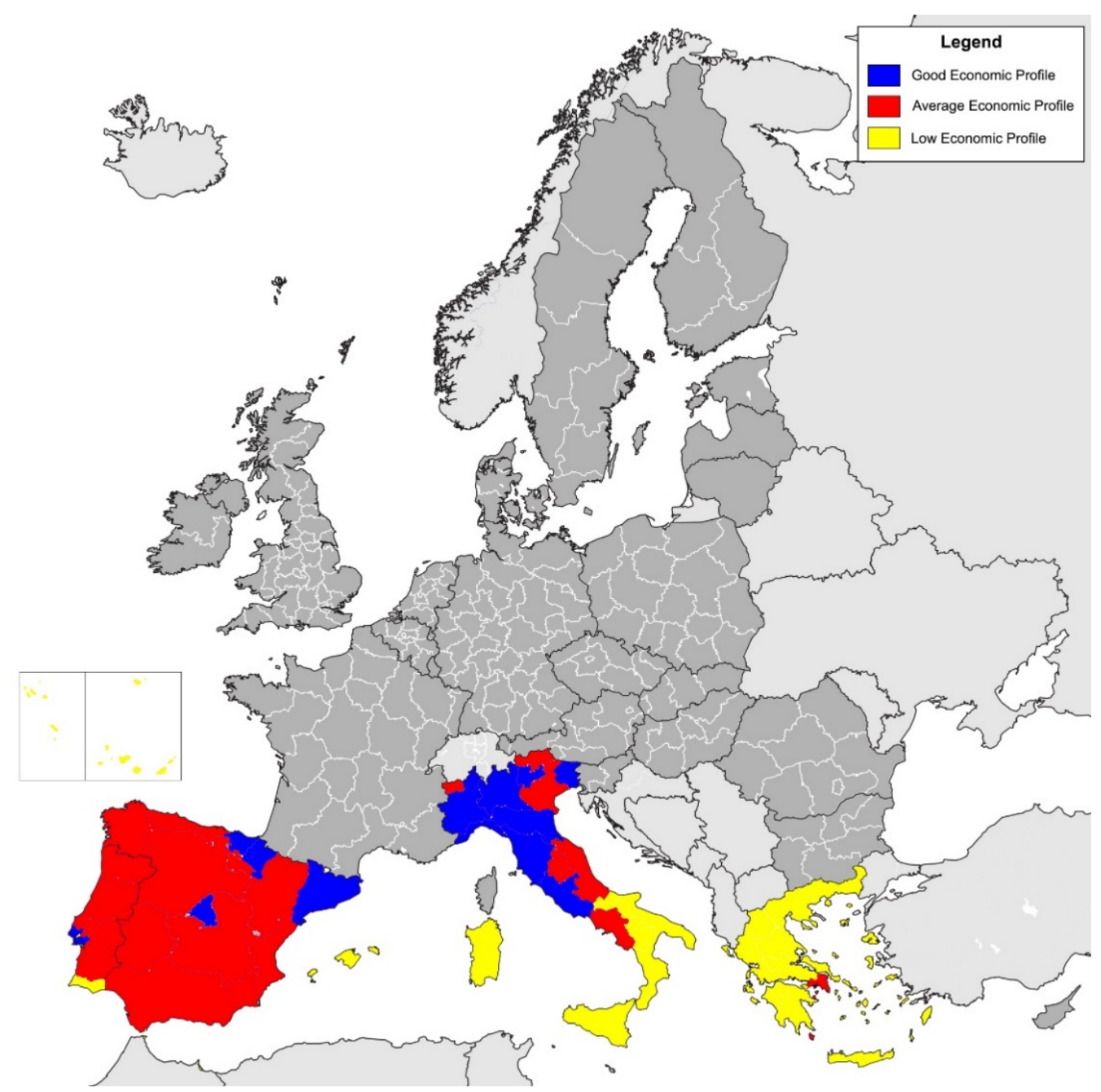

Figure 5: Clustering based on the regions' economic characteristics

countries most of the regions with high economic profile are located around the respective capital regions or other big cities. Moreover, in Spain and Italy most of those regions are located in the northern part of the country. These findings reflect the high economic activity and good economic prospects of Spain and Italy as compared to the other two countries. Portugal shows an ongoing process to improve its economic profile while Greece exhibits an almost negligible activity. Furthermore they seem to confirm the momentum of the capital regions and the north-south division in the bigger countries.

\subsection{The social profile of the south European regions}

Moving on the regions' social profile and, using the same method, we can see that according to their social characteristics the regions under study may be classified into two clusters S1 and S2 (Figure A.2). Cluster S1 contains 23 regions (i.e. 36.7\%) with higher than average Health and Education sub-indicators, but lower than average Poverty and Environmental sub-indicators. Cluster S2 contains 38 regions (i.e. 63.3\%) with higher than average Poverty and Environmental sub-indicators, but lower than average Health and Education sub-indicators. As we can see, this classification does not show any clear superiority of one cluster over the other. To clarify this situation, the clustering procedure was repeated twice on the basis of the regions Health/Education and Poverty/Environmental characteristics respectively.

According to their Health and Education characteristics the regions are classified into two clusters SC1 and SC2. The findings are summarized in Table A.4 and graphically 
Table 6: Summary Report of the clustering based on the regions' economic characteristics

\begin{tabular}{llccc}
\hline Cluster & $\begin{array}{l}\text { Economic Development } \\
\text { sub-indicator }\end{array}$ & R\&D sub-indicator & $\begin{array}{l}\text { Accessibility sub- } \\
\text { indicator }\end{array}$ \\
\hline EC1 & Mean & 1.1985 & 1.4077 & 1.2269 \\
& $\mathrm{~N}$ & 13 & 13 & 13 \\
& Std. Dev. & .06878 & .14934 & .12466 \\
EC2 & Mean & 1.0095 & 1.0227 & 1.1564 \\
& $\mathrm{~N}$ & 22 & 22 & 22 \\
& Std. Dev. & .16188 & .14065 & .11745 \\
EC3 & Mean & .8836 & .7512 & .7520 \\
& $\mathrm{~N}$ & 25 & 25 & 25 \\
& Std. Dev. & .07210 & .13860 & .15033 \\
Total & Mean & .9980 & .9930 & 1.0032 \\
& $\mathrm{~N}$ & 60 & 60 & 60 \\
& Std. Dev. & .16387 & .28703 & .25254 \\
\hline
\end{tabular}

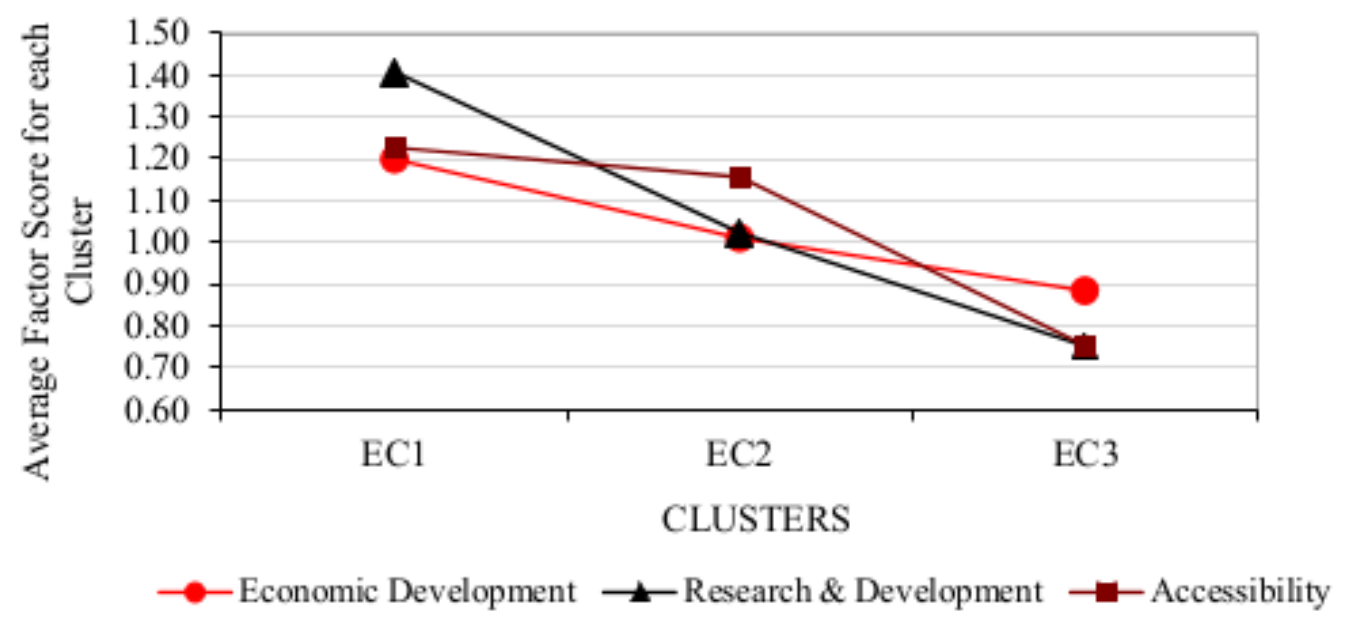

Figure 6: Cluster centers

Table 7: Regions per country. Clustering based on the regions' economic characteristics

\begin{tabular}{lccccc}
\hline \multirow{2}{*}{ Clusters } & \multicolumn{5}{c}{ Regions per country } \\
& Greece & Italy & Portugal & Spain & \multirow{2}{*}{ Total } \\
\hline EC1 & - & 8 & 1 & 4 & 13 \\
EC2 & 1 & 7 & 3 & 11 & 22 \\
EC3 & 12 & 6 & 3 & 4 & 25 \\
Total & 13 & 21 & 7 & 19 & 60 \\
\hline
\end{tabular}




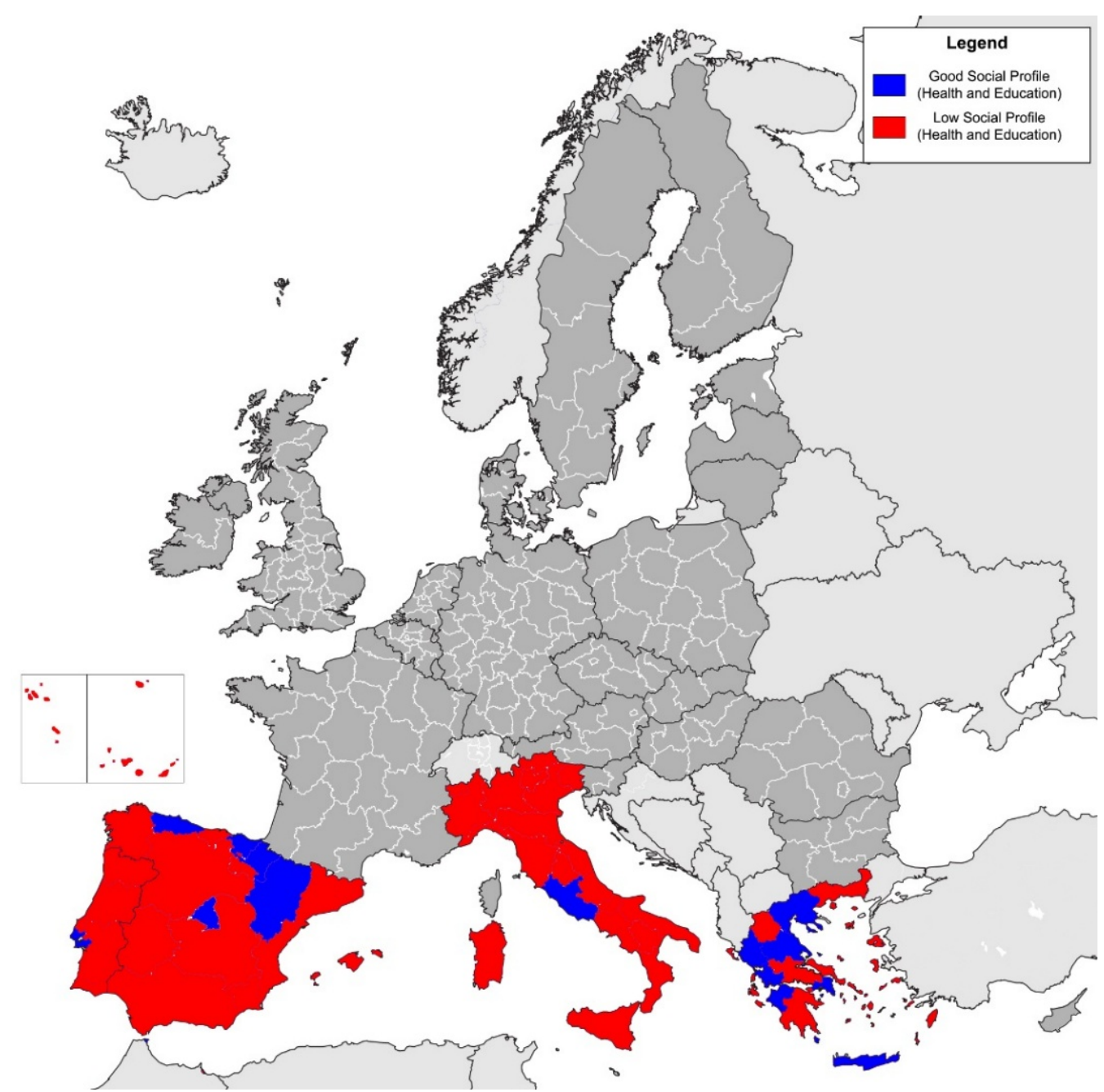

Figure 7: Clustering based on the regions' health and education characteristics

depicted in Figure 7.

In order to identify the differences between the two clusters, the following hypotheses were tested:

H0: There is no difference in the means of the health and education characteristics of the regions belonging to clusters $\mathrm{SC} 1, \mathrm{SC} 2$.

H1: There is difference in the means of the health and education characteristics of the regions belonging to clusters $\mathrm{SC} 1, \mathrm{SC} 2$.

Based on the summary report given in Table 8 , the following conclusions may be drawn:

- Cluster SC1 contains 46 regions (i.e. $76.7 \%$ ). These are regions with lower than average Health Services and Education Conditions sub-indicators. Furthermore, the dispersion of those variables' values is low in the case of both Health Services and Education Conditions (9.4\% and $10.0 \%$ respectively).

- Cluster SC2 contains 14 regions (i.e. 23.3\%). These are regions with higher than average Health and Education sub-indicators. Furthermore, the dispersion of those variables' values is low in the case of Education Conditions (8.4\%) but higher in the case of Health Services (13.1\%).

The cross tabulation (by country) leads to Table 9 . 
Table 8: Summary Report of the clustering based on the regions' health and education characteristics

\begin{tabular}{|c|c|c|c|}
\hline Cluster & & $\begin{array}{l}\text { Health Services sub-indi- } \\
\text { cator }\end{array}$ & $\begin{array}{l}\text { Education Conditions sub- } \\
\text { indicator }\end{array}$ \\
\hline \multirow[t]{3}{*}{$\mathrm{SC} 1$} & Mean & .9250 & .9793 \\
\hline & $\mathrm{N}$ & 46 & 46 \\
\hline & Std. Dev. & .08697 & .09756 \\
\hline \multirow[t]{3}{*}{$\mathrm{SC} 2$} & Mean & 1.2257 & 1.0707 \\
\hline & $\mathrm{N}$ & 14 & 14 \\
\hline & Std. Dev. & .16066 & .09025 \\
\hline \multirow[t]{3}{*}{ Total } & Mean & .9952 & 1.0007 \\
\hline & $\mathrm{N}$ & 60 & 60 \\
\hline & Std. Dev. & .16705 & .10282 \\
\hline
\end{tabular}

Table 9: Regions per country. Clustering based on the regions' health and education characteristics

\begin{tabular}{lccccc}
\hline \multirow{2}{*}{ Clusters } & Greece & Regions per country & Total \\
& 7 & 20 & 6 & Spain & 46 \\
SC1 & 6 & 1 & 1 & 6 & 14 \\
SC2 & 13 & 21 & 7 & 19 & 60 \\
Total & & & & & \\
\hline
\end{tabular}

As we can see from Table 9 and Figure 7, the cluster SC2 (i.e. the cluster of regions with better than average health and education sub-indicators), contains 14 regions or $23.3 \%$ of the total number of regions in all four countries. Almost half of the regions of Greece $(46.2 \%)$, many of the regions of Spain (31.6\%), few of the regions of Portugal $(14.3 \%)$, one of the regions of Italy $(4.8 \%)$, and no island regions (apart from Crete in Greece) belong to this cluster. Moreover, in all four countries the regions around the respective capitals belong to this cluster. Finally, apart from the capital regions, all other regions belonging to this cluster are located in the northern and more industrialized part of the respective countries. These findings reflect the ability of capital regions and regions with high economic activity to attract a larger number of educated people and provide better education and health facilities to their inhabitants. According to their poverty and environmental characteristics the regions are classified into two clusters SC3 and SC4. The findings are summarized in Table A.5 and graphically depicted in Figure 8.

In order to identify the differences between the two clusters, the following hypotheses were tested:

H0: There is no difference in the means of the poverty and environmental characteristics of the regions belonging to clusters SC3, SC4.

H1: There is difference in the means of the poverty and environmental characteristics of the regions belonging to clusters SC3, SC4.

Based on the summary report given in Table 10, the following conclusions may be drawn:

- Cluster SC3 contains 40 regions (i.e. 66.7\%). Those are regions with lower than average Poverty and Environmental Conditions sub-indicators. Furthermore, the dispersion of those variables' values is very low in the case of Poverty $(7.7 \%)$ but very high in the case of Environmental Conditions (18.1\%).

- Cluster SC4 contains 20 regions (i.e. 33.3\%). Those are regions with higher than average Poverty and Environmental Conditions sub-indicators. Furthermore, the 


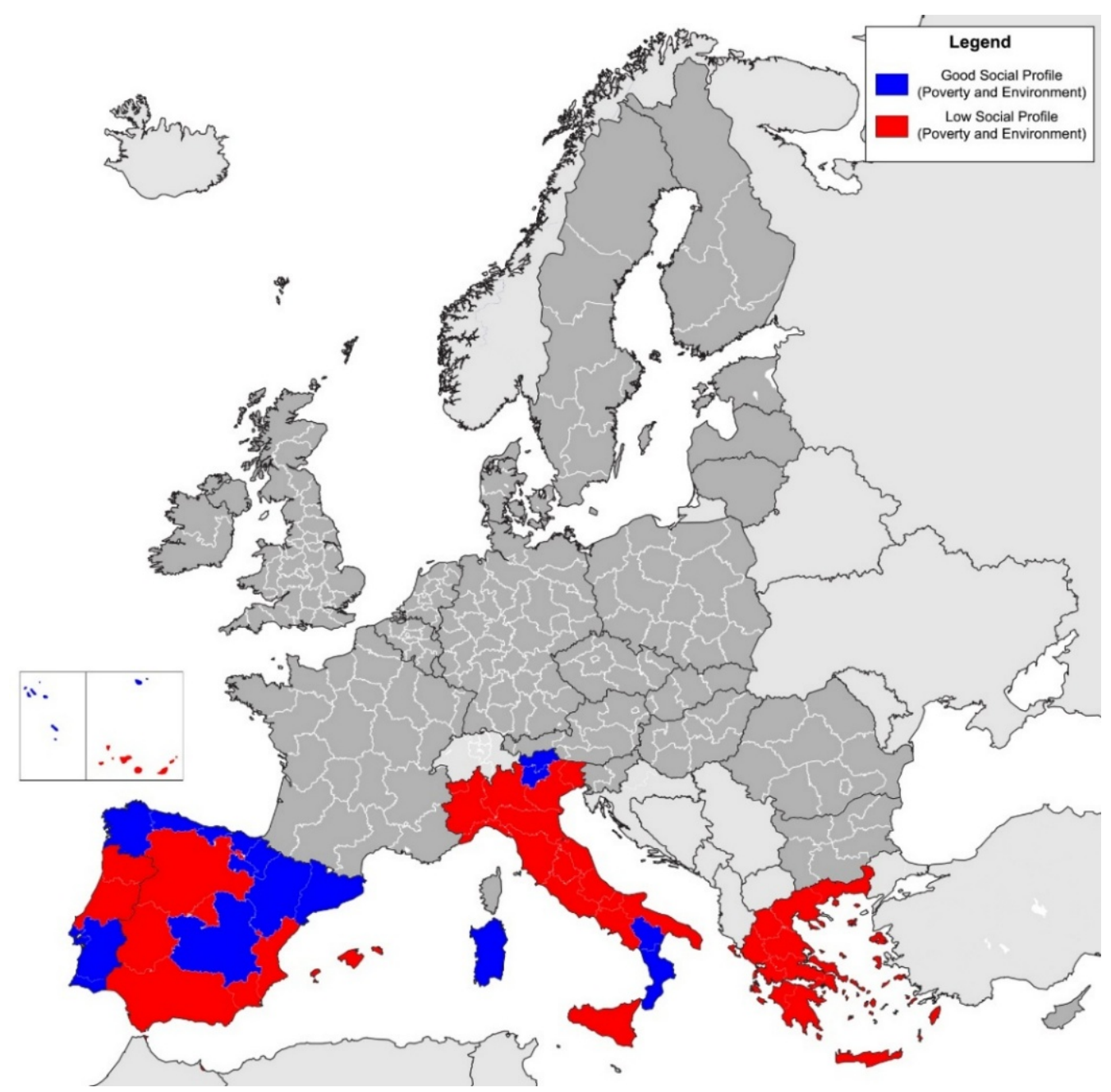

Figure 8: Clustering based on the regions' poverty and environmental characteristics

dispersion of those variables' values is very low in the case of Poverty $(7.2 \%)$ but very high in the case of Environmental Conditions (20.8\%).

- The cross tabulation (by country) leads to Table 11.

As we can see from Table 11 and Figure 8, the cluster SC4 (i.e. the cluster of regions with higher than average poverty and environmental sub-indicators) contains 20 regions (i.e. 33.3\%) of the total number of regions in all four countries. Most of the regions of Portugal (71.4\%), almost half of the regions of Spain (47.4\%), many of the regions of Italy (28.6\%), but no Greek regions belong to this cluster. Moreover, in all four countries the regions around the respective capitals do not belong to this cluster. Finally, in Spain and Italy most of these regions are located in the southern part of the countries. These findings reflect up to some extent the failure of the highly industrialized regions to offset the environmental degradation but also the low poverty and social exclusion rates of the smaller and largely self-sustainable communities. Concluding, it is worth noticing that there are only 5 regions in all countries ( 4 in Spain and 1 in Portugal) with better than average values in all four social sub-indicators.

\section{Discussion of the results - Policy implications}

The previous two sections looked at the NUTS 2 regions of the four south European countries under study. In particular, the former estimated the Economic Indicator, Social Indicator and Basic Image values for all their regions while the latter went on to the 
Table 10: Summary Report of the clustering based on the regions' poverty and environmental characteristics

\begin{tabular}{clcc}
\hline \multirow{2}{*}{ Cluster } & & Poverty sub-indicator & $\begin{array}{c}\text { Environmental Conditions } \\
\text { sub-indicator }\end{array}$ \\
\hline \multirow{2}{*}{ SC3 } & Mean & .9835 & .7460 \\
& N & 40 & 40 \\
& Std. Dev. & .07550 & .13466 \\
SC4 & Mean & 1.0370 & 1.3575 \\
& N & 20 & 20 \\
& Std. Dev. & .07491 & .28228 \\
Total & Mean & 1.0013 & .9498 \\
& N & 60 & 60 \\
& Std. Dev. & .07888 & .34950 \\
\hline
\end{tabular}

Table 11: Regions per country. Clustering based on the regions' poverty and environmental characteristics

\begin{tabular}{lccccc}
\hline \multirow{2}{*}{ Clusters } & \multicolumn{2}{l}{ Regions per country } & \multicolumn{2}{c}{ Total } \\
& Greece & Italy & Portugal & Spain & \\
\hline SC3 & 13 & 15 & 2 & 10 & 40 \\
SC4 & - & 6 & 5 & 9 & 20 \\
Total & 13 & 21 & 7 & 19 & 60 \\
\hline
\end{tabular}

clustering of those regions based on the economic and social characteristics which had been used for the estimation of their Basic Image. The four countries under study may be naturally divided into two groups, the first comprising of Spain and Italy, the bigger and more industrialized countries and the second, including Greece and Portugal, the small and less developed countries. The results confirm to a large extent this subdivision. However, it should be noted that, in some cases, Portugal seems to behave more like the two bigger countries rather than like Greece.

Based on the results of Section 5, we can say that most of the regions of Spain and Italy have high Economic Indicator values which cover a wider range thus indicating a rather strong regional heterogeneity and a lack of a dominant region. A similar range of values may be found in Portugal but with a smaller percentage of regions with high Economic Indicator and a clear gap between the leading capital region and all the rest. The presence of a dominant region is even more emphatic in Greece where the range of Economic Indicator values is much narrower and the percentage of regions with high Economic Indicator values very small. Furthermore, almost $50 \%$ of the regions of Spain and Portugal and $35 \%$ of the regions of Italy have high Social Indicator values while the respective percentage for Greece is much lower. Moreover, the Social Indicator values in all four countries extend over a narrower range, as compared to the Economic Indicator values for the reasons explained. Finally, the Basic Image values in all four countries follow a trend similar to that of the Economic Indicators. An important point, however, is the reinforcement of the gap between leading and lagging regions as a result of the described interplay between Industrial and Social Indicator values.

Moving on to the results of Section 6, it can be said that, regarding the economic characteristics (Section 6.1), almost $80 \%$ of the regions of Spain and Italy, over $50 \%$ of the regions of Portugal but only one region in Greece belong to the high economic activity cluster. These findings reflect the better economic conditions and prospects of Spain and Italy but also Portugal's effort to improve its status and Greece's almost negligible economic activity. Furthermore, the location of the regions within each country seems to confirm the momentum of the capital regions and the north-south division, especially in the big countries. Regarding the social characteristics (Section 6.2), the picture is more 
complex. Greece and Spain belong to the good health and education services cluster with Portugal and Italy to trail, whereas Portugal and Spain perform better in limiting poverty and preserving the environment, followed by Italy and Greece. Furthermore, the location of the leading and lagging regions within each country seems to confirm the ability of the capital and large regions in general to provide better health and education services and their failure to offset the environmental deterioration caused by extensive and uncontrolled industrialization but also to limit poverty and social exclusion.

The results obtained in the previous two sections may act as the basis for policy decisions. The Basic Image has been structured in such a way as to allow the researcher to detect inner changes in the region's attractiveness but also their causes. Going backwards from the Basic Image, through indicators, sub indicators, indices and sub-indices to the variables, one can identify the real causes of the Basic Image changes. Hence, the Basic Image may prove a very useful managerial tool for both regional authorities at both national and European level and business firms. The regional authorities may use the Basic Image in order to monitor the development of the various regions, get an early warning of any potential problems they may face and take the necessary measures to prevent them. The business firms on the other hand, may use the Basic Image in order to follow the development of various regions, assess their potential for future growth and take the proper location and investment decisions. Furthermore, a deeper analysis of the strengths, weaknesses, and potential prospects of the members of each one of the clusters which have been identified may lead to the drawing of policies, at a national or European level, especially designed, for the regions of each cluster.

\section{Conclusions - Suggestions for further research}

Sustainability expresses the capability of a country to satisfy the requirements of the present generation while securing, at the same time, the satisfaction of all the future generations' needs. Measuring sustainable development requires overcoming the simple one-dimensional approach of human activities and incorporating into them the social and environmental dimensions. Furthermore, new methods are needed which could benchmark performance, identify cases of fast and slow regional development and pinpoint best practices. Finally new techniques should be introduced leading to more objective, robust, and reliable decision making.

The first part of this paper, introduced the concept of a regions' Basic Image as a measure expressing a region's attractiveness and overall progress towards sustainable development. Furthermore, it presented a methodology for the estimation of a region's Basic Image. The second part used this methodology for the estimation of the Basic Image values of the NUTS 2 regions of four south European countries, namely Spain, Italy, Greece and Portugal for the year 2012 and went on to the clustering of those regions based on their economic and social characteristics.

The application gave very interesting results for the regions, within each country but also across the four countries, which were presented and discussed in the previous section. Furthermore, a number of areas of further research have been identified. A first area would be to elaborate on the definition of the regions' Economic and Social Indicators by introducing new variables as well as new data measuring, aggregation, and normalization methods and assess their impact on the changes in the Basic Image values of the regions and their clustering. A second thought would be to adjust this general model for the island regions along the lines already described. A third idea would be, as already mentioned in Section 4, to introduce a third indicator, thus expressing the Basic Image as a function of three indicators: Economic, Social, and Environmental. In such a case, the Basic Image could be modeled as a Butterfly Catastrophe. Finally, since the estimation of a region's Basic Image at a point in time gives a "snapshot" view of its development, a more interesting exercise would be to estimate it for a number of years, identify the Basic Image trend and design a policy, so as to bring it at a desired "optimum" orbit, giving at the same time an indication of the cost of its implementation. 


\section{References}

Aerts D, Czachor M, Gabora L, Kuna M, Posiewnik A, Pykacz J, Syty M (2003) Quantum morphogenesis: a variation on Thom's catastrophe theory. Physical Review E 67: 1-13. CrossRef.

Angelis V, Angelis-Dimakis A, Dimaki K (2013) A country's process of development as described by a butterfly catastrophe model. The case of European South. International Journal of Economic Sciences and Applied Research 6: 25-45

Angelis V, Angelis-Dimakis A, Dimaki K (2015) The region and its multiple images. Procedia Economics and Finance 33: 188-199. CrossRef.

Angelis V, Dimaki K (2011) A region's basic image as a measure of its attractiveness. International Journal of Economic Sciences and Applied Research 4: 7-33

Annoni P, Kozovska K (2010) EU regional competitiveness index 2010. JRC Scientific and Technical Reports, European Commission, Joint Research Centre, Institute for the Protection and Security of the Citizen

Ashworth CJ, Voogd H (1990) Selling the City. Belhaven, London

Bełej M, Kulesza S (2013) Modeling the real estate prices in Olsztyn under instability conditions. Folia Oeconomica Stetinensia 11: 61-72. CrossRef.

Boschma R, Lambooy J (1999) Why do old industrial regions decline? an exploration of potential adjustment strategies. ERSA congress, August 23-27 1999, Dublin, Ireland

Bramwell B, Rawding L (1996) Tourism marketing images of industrial cities. Annals of Tourism Research 23: 201-221. CrossRef.

Bristow G (2005) Everyone's a winner: problematising the discourse of regional competitiveness. Journal of Economic Geography 5: 285-304. CrossRef.

Bristow G (2010) Critical Reflections on Regional Competitiveness: Theory, policy and practice. Routledge, London and New York. CrossRef.

Bryson J, Daniels R, H. P (2007) The Handbook of Services Industries. Edward Elgar, Cheltenham. CrossRef.

Burgess JA (1982) Selling places: Environmental images for the executive. Regional Studies 16: 1-17. CrossRef.

Charron N, Dijkstra L, Lapuente V (2014) Regional governance matters: Quality of government within European Union Member States. Regional Studies 48: 68-90. CrossRef.

Charron N, Dijkstra L, Lapuente V (2015) Mapping the regional divide in Europe: A measure for assessing quality of government in 206 European regions. Social Indicators Research 122: 315-346. CrossRef.

del Campo C, Monteiro C, Oliveira Soares J (2008) The European regional policy and the socio-economic diversity of European regions: A multivariate analysis. European Journal of Operational Research 187: 600-612. CrossRef.

Dichter E (1985) What's an image. The Journal of Consumer Marketing 2: 75-81. CrossRef.

Dijkstra L, Annoni P, Kozovska K (2010) A new regional competitiveness index: Theory, methods and findings. Working Paper no 2/2011, European Union Regional Policy

Dou E, Ghose W (2006) A dynamic nonlinear model of online retail competition using cusp catastrophe theory. Journal of Business Research 59: 838-848. CrossRef. 
Dowling GR (1998) Measuring corporate images: A review of alternative approaches. Journal of Business Research 17: 27-37. CrossRef.

Gartner W (1993) Image formation process. Journal of Travel and Tourism Marketing 2: 191-215. CrossRef.

Gilmore R (1993) Catastrophe Theory for scientists and engineers. Wiley, New York

Huang YK (2008) The study of customer segmentation examined by catastrophe model. In: Olya M, Uda R (eds), Towards Sustainable Society on Ubiquitous Networks. Springer, Boston, 37-48

Kotler P, Asplund C, Rein I, Haider DH (1999) Marketing Places Europe. Prentice Hall, London

Kotler P, Haider DH, Irving R (1993) Marketing Places: Attracting Investment, Industry and Tourism to Cities, States and Nations. Free Press, New York

Lagas P, van Dongen F, van Rijn F, Visser H (2015) Regional quality of living in Europe. Region 2: 1-26. CrossRef.

Llewellyn J (1996) Tackling Europe's competitiveness. Oxford Review of Economic Policy 12: 87-96. CrossRef.

Lovering J (2001) The coming regional crisis (and how to avoid it). Regional Studies 35: 349-354. CrossRef.

Malecki E (2004) Jockeying for position: What it means and why it matters to regional development policy when places compete. Regional Studies 38: 1101-1120. CrossRef.

Markusen A (1996) Sticky places in slippery space: a typology of industrial districts. Economic Geography 72: 293-313. CrossRef.

Morais P, Camanho A (2011) Evaluation of performance of European cities with the aim to promote quality of life improvements. Omega 39: 398-409. CrossRef.

Poston T, Stewart I (2012) Catastrophe Theory and its Applications. Dover, New York

Rosser JB (2007) The rise and fall of catastrophe theory applications in economics: Was the baby thrown out with bathwater? Journal of Economic Dynamics and Control 10: 3255-3280. CrossRef.

Schneider B, White SE (2004) Service Quality: Research Perspective. Sage, London

Smerz KE, Guastello SJ (2008) Cusp catastrophe model for binge drinking in college population. Nonlinear Dynamics, Psychology and Life Sciences 12: 205-224

Smith M, Lancioni RA, Oliva TA (2005) The effects of management inertia on the supply chain performance of produce-to stock firms. Industrial Marketing Management 24: 614-628. CrossRef.

Thom R (1975) Structural Stability and Morphogenesis: An Outline of a General Theory of Models. Addison-Wesley, Reading M.A

van der Mass HLJ, Kolsteib R, van der Pligt J (2003) Sudden transitions in attitudes. Sociological Methods and Research 32: 395-417. CrossRef.

Wales DJ (2001) A microscopic basis for the global appearance of energy landscapes. Science 293: 602-604. CrossRef.

Zeeman EC (1973) Applications of catastrophe theory. Proceedings of the Tokyo international conference on manifolds and related topics in topology, Tokyo 


\section{A Appendix}

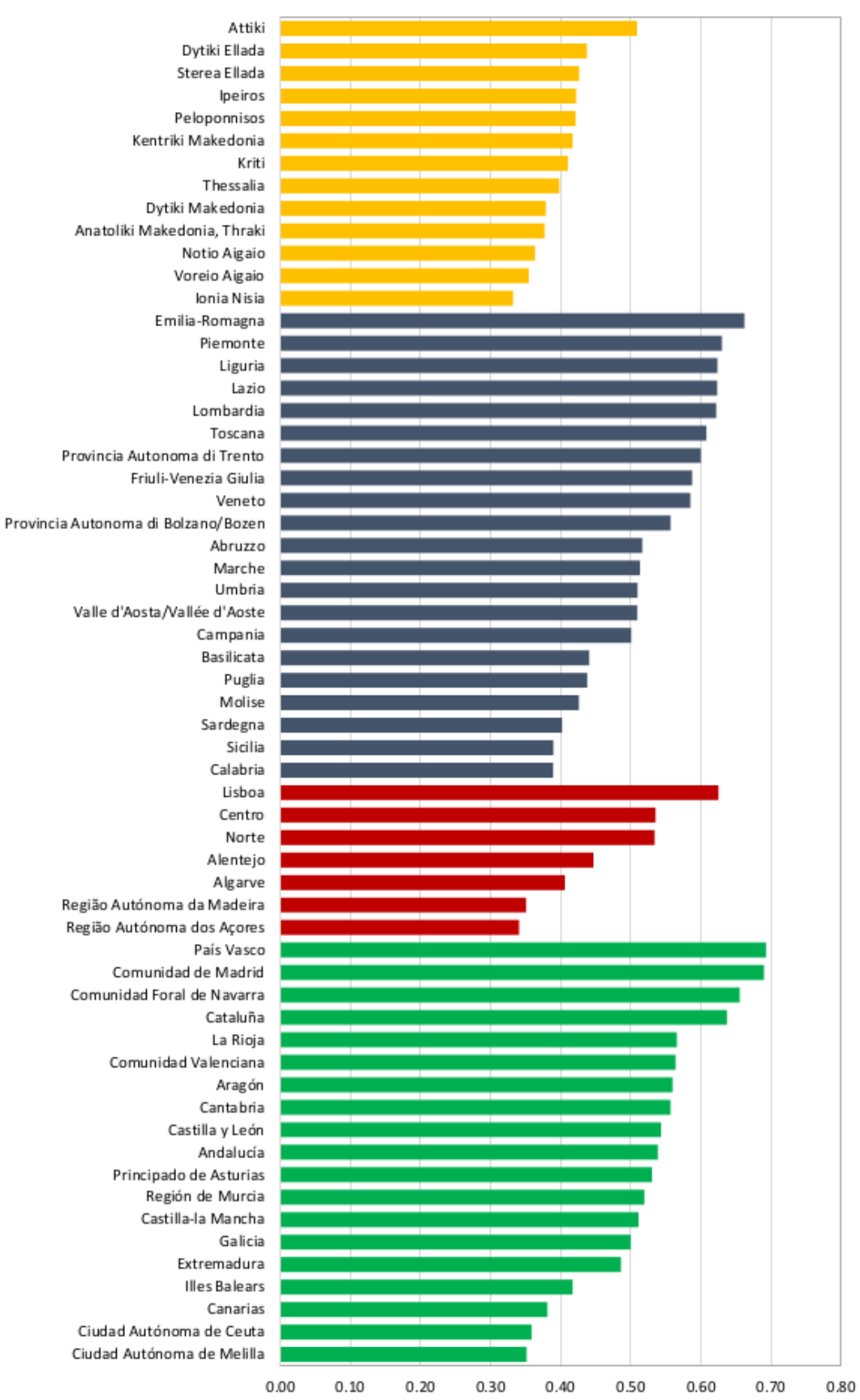

Figure A.1: The Economic Indicator of the south European regions 
Table A.1: The values of the Economic and the Social Indicators of the south European regions

\begin{tabular}{|c|c|c|}
\hline Region & Economic Indicator & Social Indicator \\
\hline \multicolumn{3}{|c|}{ GREECE } \\
\hline Anatoliki Makedonia, Thraki & 0.377 & 0.457 \\
\hline ATTIKI* & 0.509 & 0.528 \\
\hline Dytiki Ellada & 0.437 & 0.470 \\
\hline Dytiki Makedonia & 0.379 & 0.434 \\
\hline Ionia Nisia & 0.332 & 0.445 \\
\hline Ipeiros & 0.422 & 0.480 \\
\hline Kentriki Makedonia & 0.417 & 0.489 \\
\hline Kriti & 0.410 & 0.487 \\
\hline Notio Aigaio & 0.363 & 0.446 \\
\hline Peloponnisos & 0.421 & 0.453 \\
\hline Sterea Ellada & 0.427 & 0.436 \\
\hline Thessalia & 0.398 & 0.473 \\
\hline \multirow{2}{*}{\multicolumn{3}{|c|}{ Voreio Aigaio }} \\
\hline & & \\
\hline Abruzzo & 0.516 & 0.463 \\
\hline Basilicata & 0.441 & 0.532 \\
\hline Calabria & 0.389 & 0.502 \\
\hline Campania & 0.501 & 0.451 \\
\hline Emilia-Romagna & 0.662 & 0.453 \\
\hline Friuli-Venezia Giulia & 0.588 & 0.474 \\
\hline LAZIO* & 0.623 & 0.487 \\
\hline Liguria & 0.624 & 0.477 \\
\hline Lombardia & 0.622 & 0.448 \\
\hline Marche & 0.513 & 0.456 \\
\hline Molise & 0.426 & 0.475 \\
\hline Piemonte & 0.630 & 0.446 \\
\hline Provincia Autonoma di Bolzano/Bozen & 0.557 & 0.512 \\
\hline Provincia Autonoma di Trento & 0.600 & 0.554 \\
\hline Puglia & 0.438 & 0.437 \\
\hline Sardegna & 0.402 & 0.538 \\
\hline Sicilia & 0.390 & 0.456 \\
\hline Toscana & 0.608 & 0.461 \\
\hline Umbria & 0.510 & 0.481 \\
\hline Valle d'Aosta & 0.510 & 0.580 \\
\hline Veneto & 0.585 & 0.455 \\
\hline \multicolumn{3}{|c|}{ PORTUGAL } \\
\hline Alentejo & 0.447 & 0.457 \\
\hline Algarve & 0.406 & 0.520 \\
\hline Centro & 0.535 & 0.473 \\
\hline LISBOA* & 0.625 & 0.533 \\
\hline Norte & 0.534 & 0.472 \\
\hline Região Autónoma da Madeira & 0.351 & 0.531 \\
\hline \multirow{2}{*}{\multicolumn{3}{|c|}{ Região Autónoma dos Açores }} \\
\hline & & \\
\hline Andalucía & 0.539 & 0.453 \\
\hline Aragón & 0.560 & 0.541 \\
\hline Canarias & 0.381 & 0.416 \\
\hline Cantabria & 0.557 & 0.569 \\
\hline Castilla y León & 0.543 & 0.503 \\
\hline Castilla-la Mancha & 0.511 & 0.497 \\
\hline Cataluña & 0.637 & 0.507 \\
\hline Ciudad Autónoma de Ceuta & 0.358 & 0.457 \\
\hline Ciudad Autónoma de Melilla & 0.351 & 0.412 \\
\hline COMUNIDAD DE MADRID* & 0.690 & 0.491 \\
\hline Comunidad Foral de Navarra & 0.656 & 0.599 \\
\hline Comunidad Valenciana & 0.564 & 0.477 \\
\hline Extremadura & 0.486 & 0.442 \\
\hline Galicia & 0.500 & 0.516 \\
\hline Illes Balears & 0.417 & 0.412 \\
\hline La Rioja & 0.566 & 0.520 \\
\hline País Vasco & 0.693 & 0.581 \\
\hline Principado de Asturias & 0.530 & 0.571 \\
\hline Región de Murcia & 0.519 & 0.473 \\
\hline
\end{tabular}


Table A.2: The Basic Image values of the south European regions

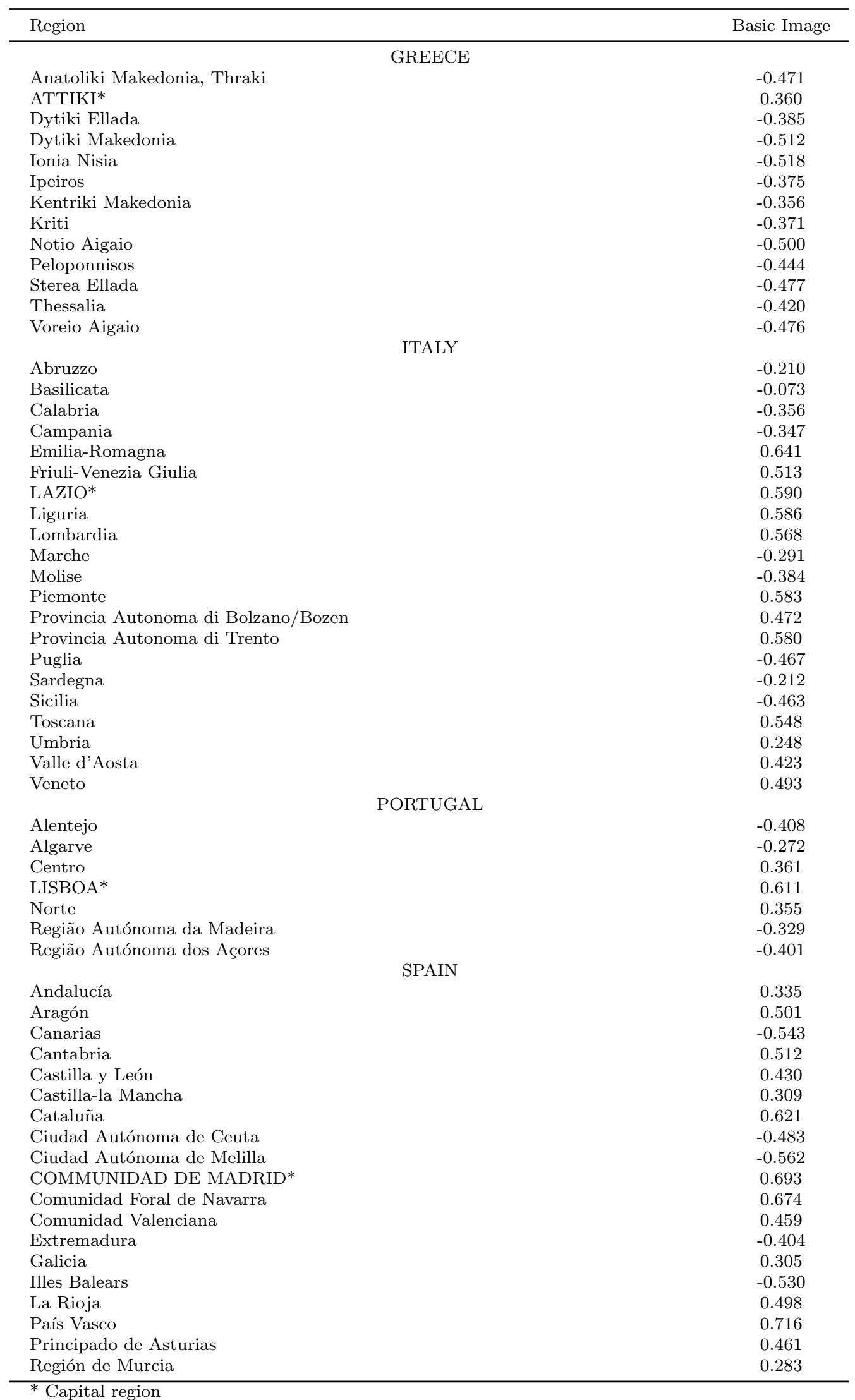


Table A.3: Clustering based on the economic characteristics of the south European regions

\begin{tabular}{|c|c|c|}
\hline Cluster & Country & Region \\
\hline $\mathrm{EC} 1$ & $\begin{array}{l}\text { Spain } \\
\text { Italy } \\
\text { Portugal }\end{array}$ & $\begin{array}{l}\text { País Vasco, Comunidad de Madrid, Comunidad Foral de Navarra, } \\
\text { Cataluña } \\
\text { Emilia-Romagna, Piemonte, Liguria, Lazio, Lombardia, Toscana, } \\
\text { Provincia Autonoma di Trento, Friuli-Venezia Giulia } \\
\text { Lisboa }\end{array}$ \\
\hline $\mathrm{EC} 2$ & $\begin{array}{l}\text { Italy } \\
\text { Greece } \\
\text { Portugal }\end{array}$ & $\begin{array}{l}\text { La Rioja, Comunidad Valenciana, Aragón, Cantabria, Castilla y } \\
\text { León, Andalucía, Principado de Asturias, Región de Murcia, } \\
\text { Castilla-la Mancha, Galicia, Extremadura } \\
\text { Veneto, Provincia Autonoma di Bolzano/Bozen, Abruzzo, } \\
\text { Marche, Umbria, Valle d'Aosta, Campania } \\
\text { Attiki } \\
\text { Centro, Norte, Alentejo }\end{array}$ \\
\hline EC3 & $\begin{array}{l}\text { Spain } \\
\text { Italy } \\
\text { Greece }\end{array}$ & $\begin{array}{l}\text { Illes Balears, Canarias, Ciudad Autónoma de Ceuta, Ciudad } \\
\text { Autónoma de Melilla } \\
\text { Basilicata, Puglia, Molise, Sardegna, Sicilia, Calabria } \\
\text { Dytiki Ellada, Sterea Ellada, Ipeiros, Peloponnisos, Kentriki } \\
\text { Makedonia, Kriti, Thessalia, Dytiki Makedonia, Anatoliki } \\
\text { Makedonia - Thraki, Notio Aigaio, Voreio Aigaio, Ionia Nisia } \\
\text { Algarve, Região Autónoma da Madeira, Região Autónoma dos } \\
\text { Açores }\end{array}$ \\
\hline
\end{tabular}

Table A.4: Clustering based on Health and Education characteristics of the south European regions

\begin{tabular}{lll}
\hline Cluster & Country & Region \\
\hline SC1 & Spain & Andalucía, Canarias, Cantabria, Castilla y León, Castilla-la \\
& & Mancha, Cataluña, Ciudad Autónoma de Melilla, Comunidad \\
& & Valenciana, Extremadura, Galicia, Illes Balears, La Rioja, \\
& Región de Murcia \\
& Abruzzo, Basilicata, Calabria, Campania, Emilia-Romagna, \\
& & Friuli-Venezia Giulia, Liguria, Lombardia, Marche, Molise, \\
& & Piemonte, Provincia Autonoma di Bolzano/Bozen, Provincia \\
& Autonoma di Trento, Puglia, Sardegna, Sicilia, Toscana, Umbria, \\
& Valle d'Aosta, Veneto \\
& Anatoliki Makedonia - Thraki, Dytiki Makedonia, Ionia Nisia, \\
& Notio Aigaio, Peloponnisos, Sterea Ellada, Voreio Aigaio \\
& Plentejo, Algarve, Centro, Norte, Região Autónoma da Madeira, \\
& Região Autónoma dos Açores \\
& Spain & Aragón, Ciudad Autónoma de Ceuta, Comunidad de Madrid, \\
& Comunidad Foral de Navarra, País Vasco, Principado de Asturias \\
& Italy & Lazio \\
& Greece & Attiki, Dytiki Ellada, Ipeiros, Kentriki Makedonia, Kriti, \\
& Thessalia \\
& Portugal & Lisboa
\end{tabular}


Table A.5: Clustering based on Poverty and Environmental characteristics of the south European regions

\begin{tabular}{|c|c|c|}
\hline Cluster & Country & Region \\
\hline \multirow[t]{6}{*}{ SC3 } & Spain & $\begin{array}{l}\text { Andalucía, Canarias, Castilla y León, Ciudad Autónoma de } \\
\text { Ceuta, Ciudad Autónoma de Melilla, Comunidad de Madrid, } \\
\text { Comunidad Valenciana, Extremadura, Illes Balears, Región de } \\
\text { Murcia }\end{array}$ \\
\hline & Italy & $\begin{array}{l}\text { Abruzzo, Campania, Emilia-Romagna, Friuli-Venezia Giulia, } \\
\text { Lazio, Liguria, Lombardia, Marche, Molise, Piemonte, Puglia, } \\
\text { Sicilia, Toscana, Umbria, Veneto }\end{array}$ \\
\hline & Greece & Anatoliki Makedonia - Thraki, Attiki, Dytiki Ellada, Dytiki \\
\hline & & Makedonia, Ionia Nisia, Ipeiros, Kentriki Makedonia, Kriti, Notio \\
\hline & & Aigaio, Peloponnisos, Sterea Ellada, Thessalia, Voreio Aigaio \\
\hline & Portugal & Centro, Norte \\
\hline \multirow[t]{3}{*}{$\mathrm{SC} 4$} & Spain & $\begin{array}{l}\text { Aragón, Cantabria, Castilla-la Mancha, Cataluña, Comunidad } \\
\text { Foral de Navarra, Galicia, La Rioja, País Vasco, Principado de } \\
\text { Asturias }\end{array}$ \\
\hline & Italy & $\begin{array}{l}\text { Basilicata, Calabria, Provincia Autonoma di Bolzano/Bozen, } \\
\text { Provincia Autonoma di Trento, Sardegna, Valle d'Aosta }\end{array}$ \\
\hline & Portugal & $\begin{array}{l}\text { Alentejo, Algarve, Lisboa, Região Autónoma da Madeira, Região } \\
\text { Autónoma dos Açores }\end{array}$ \\
\hline
\end{tabular}

Table A.6: Overall classification of the south European regions based on their Basic Image

\begin{tabular}{|c|c|c|}
\hline Interval & Country & Region \\
\hline$[-1.0,-0.5)$ & $\begin{array}{l}\text { Spain } \\
\text { Greece }\end{array}$ & $\begin{array}{l}\text { Canarias, Ciudad Autónoma de Melilla, Illes Balears } \\
\text { Dytiki Makedonia, Ionia Nisia, Notio Aigaio }\end{array}$ \\
\hline$[-0.5,0)$ & $\begin{array}{l}\text { Spain } \\
\text { Italy } \\
\text { Greece }\end{array}$ & $\begin{array}{l}\text { Extremadura, Ciudad Autónoma de Ceuta } \\
\text { Basilicata, Calabria, Campania, Marche, Molise, Puglia, } \\
\text { Sardegna, Sicilia } \\
\text { Kentriki Makedonia, Kriti, Ipeiros, Dytiki Ellada, } \\
\text { Thessalia, Peloponnisos, Anatoliki Makedonia - Thraki, } \\
\text { Voreio Aigaio, Sterea Ellada } \\
\text { Algarve, Região Autónoma da Madeira, Região } \\
\text { Autónoma dos Açores, Alentejo }\end{array}$ \\
\hline$[0,0.5)$ & $\begin{array}{l}\text { Italy } \\
\text { Greece } \\
\text { Portugal }\end{array}$ & $\begin{array}{l}\text { Andalucía, Castilla-la Mancha, Castilla y León, } \\
\text { Comunidad Valenciana, Galicia, Principado de Asturias, } \\
\text { Región de Murcia } \\
\text { Abruzzo, Provincia Autonoma di Bolzano/Bozen, Umbria, } \\
\text { Valle d'Aosta, Veneto } \\
\text { ATTIKI } \\
\text { Centro, Norte }\end{array}$ \\
\hline$[0.5,1.0)$ & Portugal & $\begin{array}{l}\text { Aragón, Cantabria, Cataluña, COMUNIDAD DE } \\
\text { MADRID, Comunidad Foral de Navarra, La Rioja, País } \\
\text { Vasco } \\
\text { Emilia-Romagna, Friuli-Venezia Giulia, LAZIO, Liguria, } \\
\text { Lombardia, Piemonte, Provincia Autonoma di Trento, } \\
\text { Toscana } \\
\text { LISBOA }\end{array}$ \\
\hline
\end{tabular}




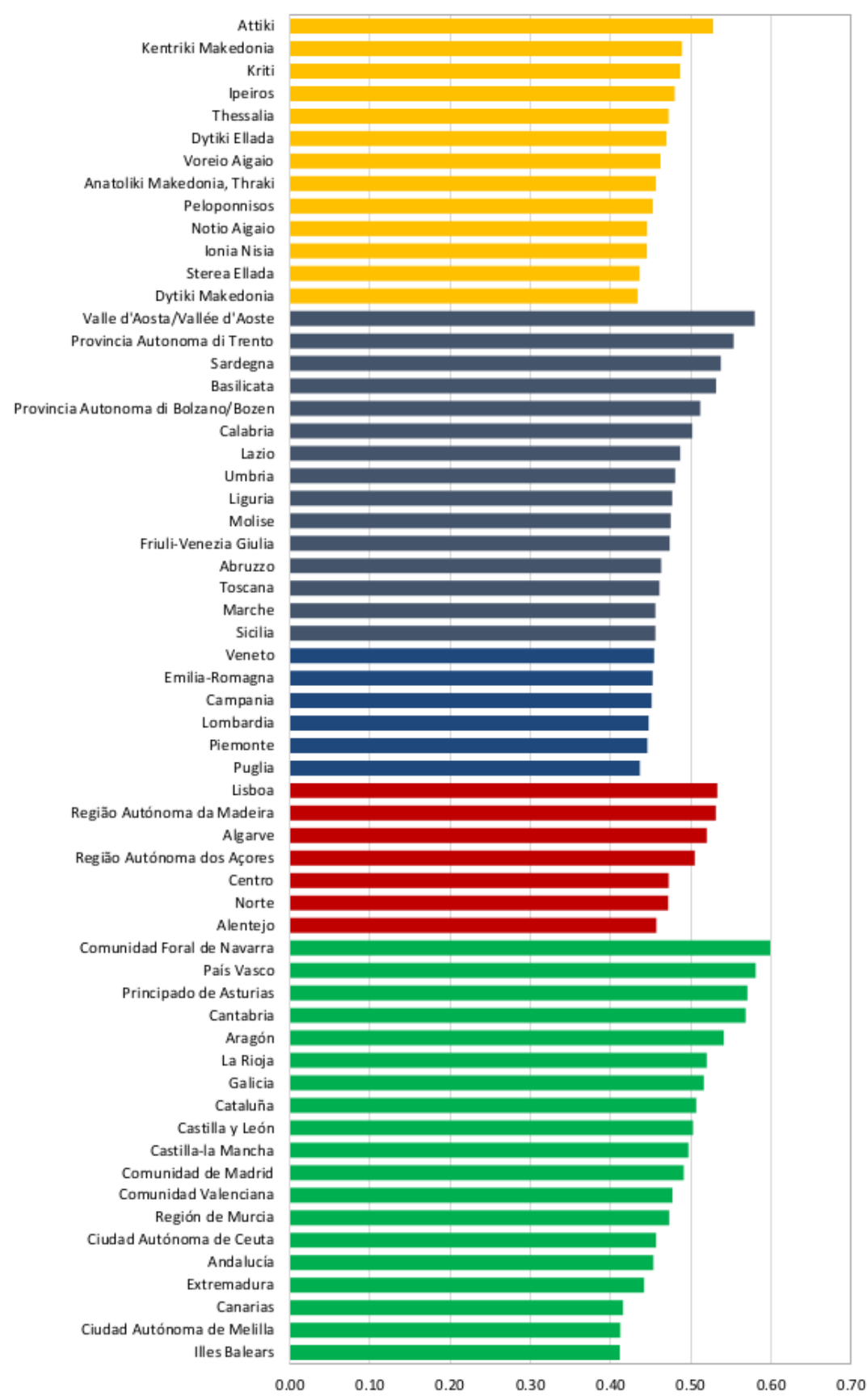

Figure A.2: The Social Indicator of the south European regions 

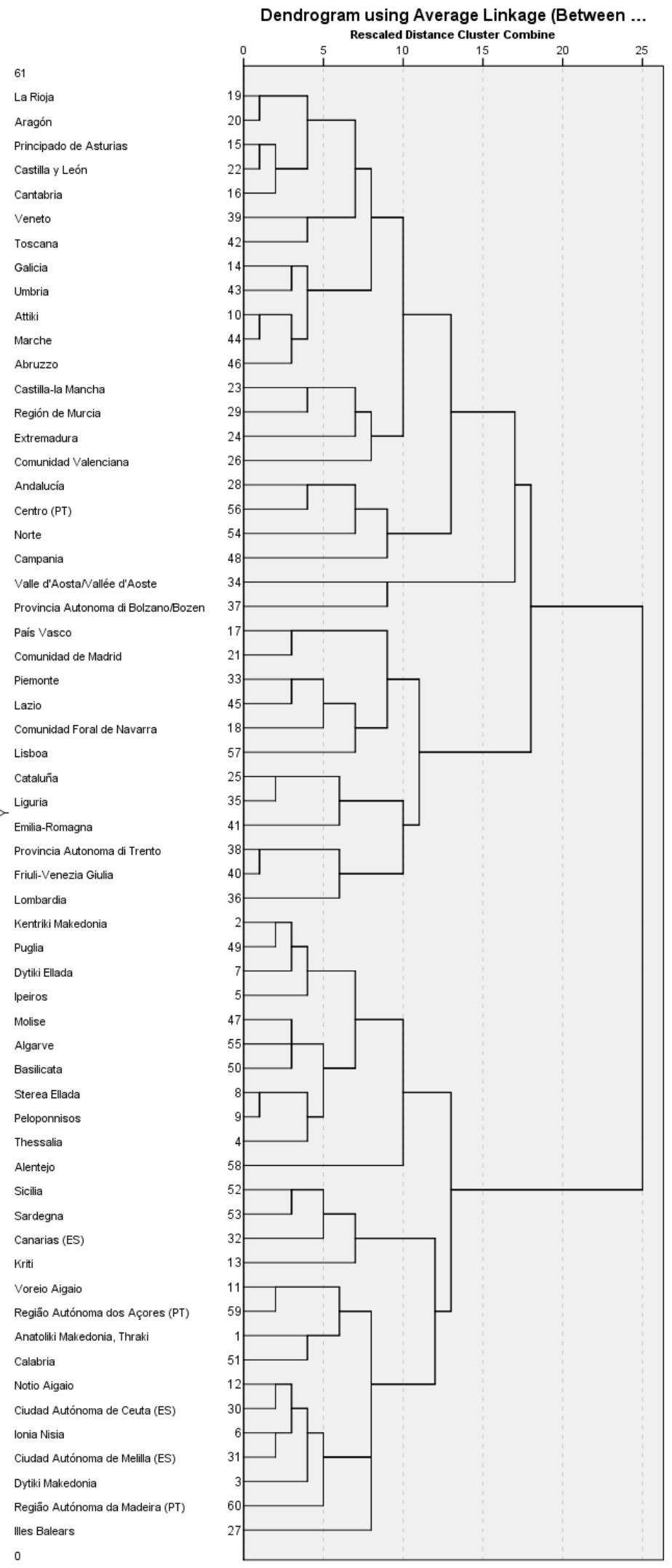

Figure A.3: Dendrogram based on the economic characteristics of the south European regions 


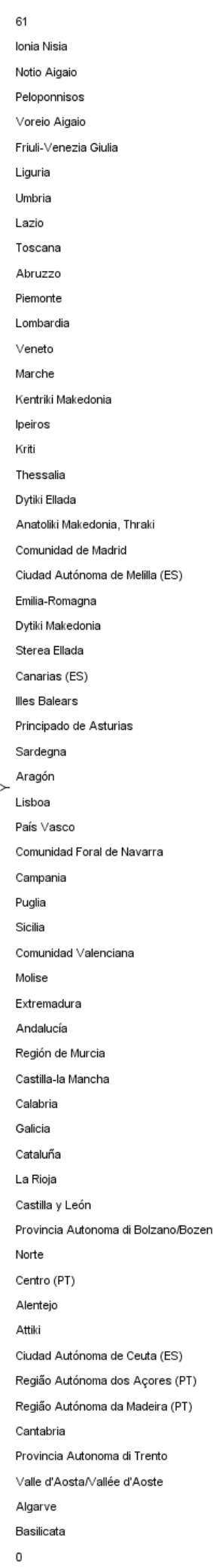

Dendrogram using Average Linkage (Between ...

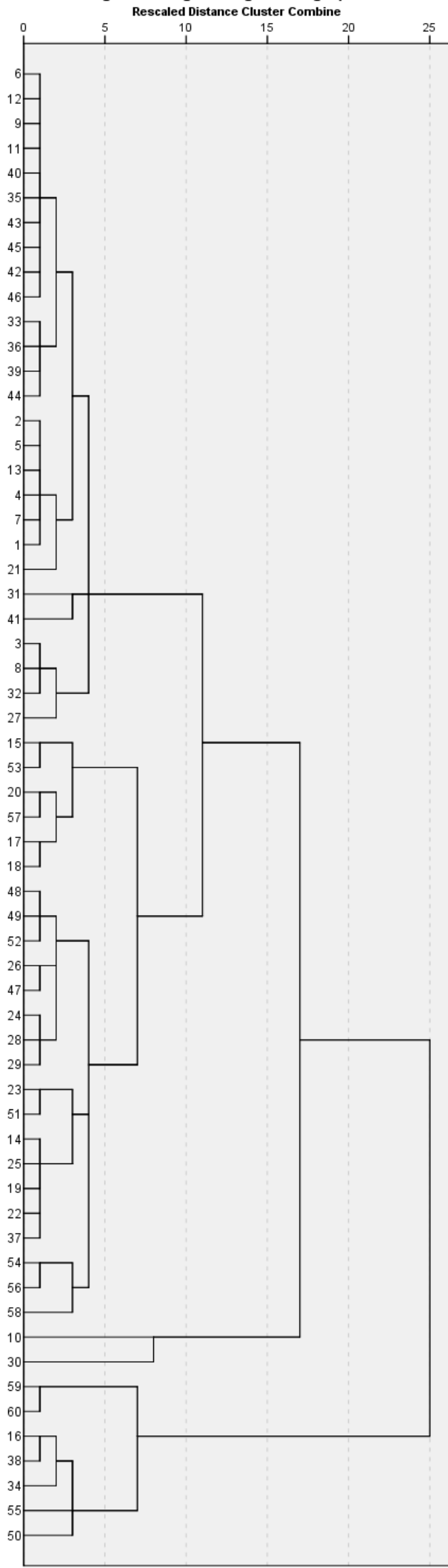

Figure A.4: Dendrogram based on the social characteristics of the south European regions 